\title{
New Approach for Calculating the Effective Dielectric Constant of the Moist Soil for Microwaves
}

\author{
Chang-Hwan Park 1,2,* (i), Andreas Behrendt ${ }^{1}$, Ellsworth LeDrew ${ }^{3}$ and Volker Wulfmeyer ${ }^{1}$ \\ 1 Institute of Physics and Meteorology, University of Hohenheim, Stuttgart 70599, Germany; \\ andreas.behrendt@uni-hohenheim.de (A.B.); volker.wulfmeyer@uni-hohenheim.de (V.W.) \\ 2 Center for Applied Geoscience, University of Tübingen, Tübingen 72076, Germany \\ 3 Geography and Environmental Management, University of Waterloo, Waterloo, ON N2L 3G1, Canada; \\ ells@uwaterloo.ca \\ * Correspondence: ecomm77@gmail.com or chpark2@kma.go.kr; Tel.: +82-10-4206-2058
}

Received: 7 May 2017; Accepted: 11 July 2017; Published: 15 July 2017

\begin{abstract}
Microwave remote sensing techniques are used, among others, for temporally and spatially highly-resolved observations of land-surface properties, e.g., for the management of agricultural productivity and water resource, as well as to improve the performances of numerical weather prediction and climate simulations with soil moisture data. In this context, the effective dielectric constant of the soil is a key variable to quantify the land surface properties. We propose a new approach for the effective dielectric constant of the multiphase soil that is based on an arithmetic average of the dielectric constants of the land-surface components with damping. The results show, on average, better agreement with experimental data than previous approaches. Furthermore, the proposed new model overcomes the theoretical limitation of previous models in the incorporation of non-physical parameters to simulate measured data experimentally with satisfactory accuracy. For microwave remote sensing such as SMAP (Soil Moisture Active Passive), SMOS (Soil Moisture and Ocean Salinity) and AMSR-E (Advanced Microwave Scanning Radiometer for EOS), the physical-based model in our study showed a 23-35\% RMSE (root-mean-square error) reduction compared to the most prevalent refractive mixing model in the prediction of the dielectric constant for the real and imaginary part, respectively. Furthermore, in radiowave bands used in portable soil sensors such as TDR (time-domain reflectometer) and GPR (ground-penetrating radar) the new dielectric mixing model reduced RMSE by up to $53 \%$ in the prediction of the dielectric constant. We found that the permittivity over the saturation point (porosity of dry soil) has a very different and varying pattern compared to that measured in the unsaturated condition. However, in our study, this pattern was mathematically derived from the same mixing rule applied for the unsaturated condition. It is expected that the new dielectric mixing model might help to improve the accuracy of flood monitoring by satellite.
\end{abstract}

Keywords: soil moisture; relative permittivity; dielectric constant; refractive index; passive microwave remote sensing; SMOS; SMAP; AMSR-E

\section{Introduction}

In contrast to radiation in the visible and IR spectral regions, microwaves generally penetrate non-precipitating clouds and the gaseous atmosphere without strong interaction (with the exception only of some microwave regions at which absorption by some gases takes place). Therefore, microwaves allow for reliable information about the soil properties and temperatures of the terrestrial surface, as well as of vegetation independent of cloud cover. Furthermore, microwave remote sensing data enable us to reduce the uncertainties of remote sensing observations made at other wavelengths regarding the land surface for improved estimations of atmospheric trace gases, aerosols and clouds. 
In summary, we can thus state that the understanding of the interaction of microwaves is important, not only for land surface remote sensing, but also for observations of the Earth system as a whole.

In modern space-borne microwave remote sensing [1], several bands are used: L-band (1-2 GHz), C-band (4-8 GHz), X-band (8-12 GHz) and K-band (12-40 GHz). The accurate computation of the effective dielectric constant is essential for both passive and active microwave sensors. Furthermore, it is also critical for the analysis of materials in materials sciences [2]. The first dielectric mixing formulas were proposed for cavities, which are (hypothetical) spheres [3,4], monodispersed spheres [5], polydispersed spheres [6], non-spherical [7], as well as for non-spherical nanoporous media and nanoparticles [8,9]. However, these mixing models contain an innate limitation for complex multiphase materials such as moist soil: the practical design of the dielectric mixing model based on a microgeometry approach relies on empirical adjustments [2]. When a material is exposed to an electric field, its dielectric constant describes the interaction. Thus, the remote sensing of land-surface properties, such as soil moisture, requires an effective operator for the computation of the effective dielectric constant (Figure 1).

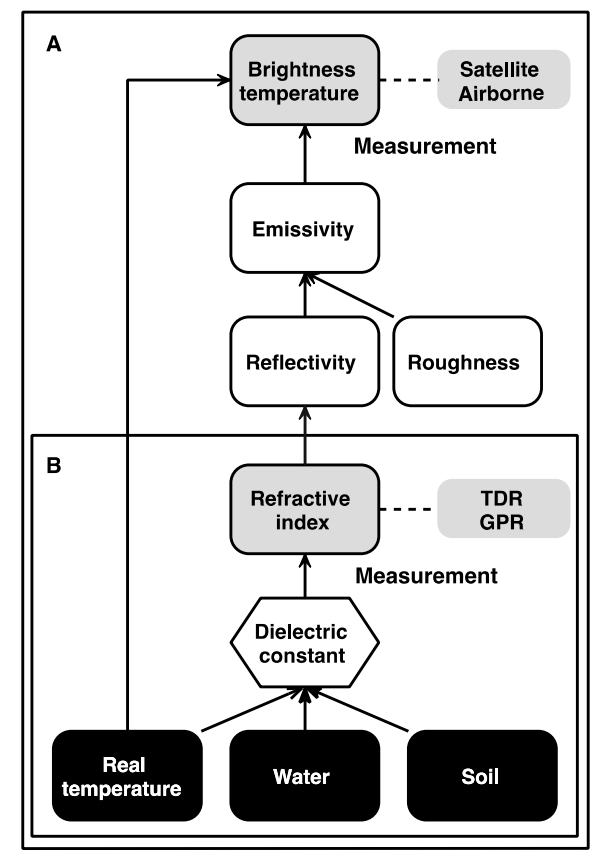

Figure 1. Measuring principles of bare soil properties (black boxes) by satellite and airborne remote sensing in the microwave region (A) and TDR (time-domain reflectometer) and GPR (ground-penetrating radar) (B). The dielectric constant (hexagon) is the link between the measured parameters of the sensors (brightness temperature (TB) and refractive index, respectively) and the targeted soil properties.

TDR (time-domain reflectometer) and GPR (ground-penetrating radar) measure the refractive index, compute the effective dielectric constant and quantify the soil water content by using the separately-obtained temperature and soil texture information. In contrast to this, airborne and space-borne remote sensing instruments measure the brightness temperature TB (Box A in Figure 1). To retrieve the soil moisture content from the measured $\mathrm{TB}$, the traditional retrieval method requires ancillary information to account for soil temperature and soil texture, as well as for the effects of vegetation. Studies have attempted to obtain this ancillary data for vegetation from the vegetation parameter $b$ [10], multi-frequency microwave sensor measurements [11-13], the NDVI (normalized differenced vegetation index) [14] or the MPDI (microwave polarization difference index) [15-17]. However, the measurement of land-surface properties is already very uncertain for bare soil without vegetation. Hence, for this simpler situation, the ancillary information about soil temperature and 
soil texture is already quite critical for retrieving the soil moisture content. As a consequence, we focus in this study on the bare soil. The simulation results are validated with TDR measurements. Future studies may extend the new dielectric mixing model presented here to ground vegetation and canopy layers.

The dielectric mixing model introduced here can be integrated into land surface models. All of the information that is necessary for calculating TB is available in the land surface model (such as soil temperature, soil moisture [18] and soil texture [19]). Thus, the new mixing model can be used in the future within a forward operator for determining TB. Recently, new "physically-based" radiative transfer models were proposed $[14,16,20]$ for the retrieval of near surface soil moisture from passive microwave measurements. These can be better combined with data assimilation [21-23], especially for the estimation of the root zone soil moisture using SMOS [24,25] and SMAP [26,27]. By combining our dielectric mixing model with the radiative transfer models, the TB can be obtained more accurately in the microwave spectral region, which is of course beneficial not only for the data assimilation scheme but also the field campaign for the calibration and validation such as SMOSREX [28] or SMAPVEX [29].

This paper is organized as follows: In Section 2, we propose a new multiphase model for the effective dielectric constant; the damping factor and the dielectric constant of the bound water are discussed. In Section 3, we apply the new model and compare the results with experimental data. Finally, a discussion and the conclusion of this study are given in Sections 4 and 5.

\section{Materials and Method}

\subsection{Single-Phase Dielectric Mixing Model}

For land surface remote sensing, two mixing theories have been proposed, namely the 'dielectric average' originally proposed by Brown [30]:

$$
\varepsilon_{\text {eff }}=\sum_{j=1}^{m} \mathrm{v}_{j} \varepsilon_{j}
$$

and the 'refractive average' originally proposed by Birchak [31]:

$$
\mathrm{n}_{\text {eff }}=\sum_{\mathrm{j}=1}^{\mathrm{m}} \mathrm{v}_{\mathrm{j}} \mathrm{n}_{\mathrm{j}}=\sum_{\mathrm{j}=1}^{\mathrm{m}} \mathrm{v}_{\mathrm{j}} \sqrt{\varepsilon_{\mathrm{j}}}
$$

Both approaches relate the effective dielectric constant $\varepsilon_{\text {eff }}$ of a material to the dielectric constants $\varepsilon_{j}$ of its $m$ different components weighted according to their volumetric fractions $v_{j}$ in the mixture. The refractive index $n_{\text {eff }}$ measured by TDR or GPR is related to the time duration of electromagnetic wave propagation in a medium, in our case in the soil-water mixture [32], according to:

$$
\mathrm{n}_{\mathrm{eff}}=\frac{\mathrm{ct}}{2 \mathrm{~L}}
$$

where $\mathrm{c}$ is the speed of light, $\mathrm{t}$ is the traveling time along the probe rod and $\mathrm{L}$ is the length of the probe rod. A further refinement proposed by Ansoult et al. [33] and by Dobson et al. [34] is the empirical modification of Equation (1) with an exponent $\alpha$, the so-called 'shape factor', according to:

$$
\varepsilon_{\text {eff }}^{\alpha}=\sum_{j=1}^{m} \mathrm{v}_{j} \varepsilon_{j}^{\alpha}
$$

The linear relationship of the soil moisture with the refractive index, similar to Equation (2), has been widely used in calibration models [35-38]. This approach has further evolved into various power-law-based models: because the soil moisture estimation following Equation (2) could not meet the required accuracy for different soil textures and frequencies of electromagnetic waves, various values have been proposed for $\alpha[33,34,39-46]$. Furthermore, a nonlinear relationship between water content and the dielectric constant has been proposed for empirical calibration models [47-49]. Figure 2 gives an overview of these models together with the different values used for $\alpha$. In Appendix A, 
we discuss that the effective refractive index $\mathrm{n}_{\mathrm{eff}}$ should preferably be calculated from the effective dielectric constant $\varepsilon_{\text {eff }}$ based on the arithmetic mean (parallel mixing) according to Equation (1), and not (2) or (4).

\begin{tabular}{|c|c|c|c|c|c|c|c|c|c|}
\hline \multicolumn{2}{|c|}{ M ic rog eom etry } & \multicolumn{2}{|c|}{$D$ ie lectric $m$ ix ing } & \multicolumn{4}{|c|}{$R$ efractive $m$ ix in $g$} & \multicolumn{2}{|c|}{ Calibration m ode 1} \\
\hline $\begin{array}{l}\text { Spherical } \\
\text { incursion }\end{array}$ & $\begin{array}{c}\text { Clausius } \\
- \text { Mossotti } \\
(1850)\end{array}$ & $\begin{array}{c}\text { Main-phase } \\
\text { mixing }\end{array}$ & $\begin{array}{r}\text { B rown } \\
(1956)\end{array}$ & \multicolumn{2}{|c|}{$\begin{array}{c}\text { Main-phase } \\
\text { mixing }\end{array}$} & $\begin{array}{c}\text { Birchak } \\
\text { et al. } \\
\text { (1974) }\end{array}$ & & $\begin{array}{c}\text { Mineral } \\
\text { soil }\end{array}$ & $\begin{array}{l}\text { Topp } \\
\text { et al. } \\
(1980)\end{array}$ \\
\hline $\begin{array}{c}\text { Main-phase } \\
\text { mixing }\end{array}$ & $\begin{array}{l}\text { Rayleigh } \\
\text { (1892) }\end{array}$ & $\begin{array}{c}\text { Semi-empirical } \\
\text { multi-phase } \\
\text { mixing }\end{array}$ & $\begin{array}{c}\text { Wang \& } \\
\text { Schumugge } \\
(1980)\end{array}$ & $\begin{array}{c}\text { Calibration } \\
\text { model }\end{array}$ & $\begin{array}{l}\text { Ledieu } \\
\text { et al. } \\
\text { (1986) }\end{array}$ & $\begin{array}{l}\text { Ansoult } \\
\text { et al. } \\
\text { (1984) }\end{array}$ & \multirow[t]{2}{*}{$\begin{array}{c}\text { Semi- } \\
\text { empirical } \\
\text { Power-law }\end{array}$} & $\begin{array}{c}\text { Organic } \\
\text { soil }\end{array}$ & $\begin{array}{l}\text { Roth } \\
\text { et al. } \\
\text { (1992) }\end{array}$ \\
\hline & & & 1.0 & & 0.5 & $-1.0 \sim 1.0$ & & & \\
\hline $\begin{array}{l}\text { Mono- } \\
\text { dispersed }\end{array}$ & $\begin{array}{l}\text { Maxwell } \\
\text {-Garnett } \\
(1904) \\
\end{array}$ & & & & $\begin{array}{l}\text { Herkelrath } \\
\text { et al. } \\
\text { (1991) }\end{array}$ & $\begin{array}{l}\text { Dobson } \\
\text { et al. } \\
(1985)\end{array}$ & & \multirow[t]{20}{*}{$\begin{array}{l}\text { Empirical } \\
\text { quadratic } \\
\text { fitting }\end{array}$} & $\begin{array}{l}\text { Hallikainen } \\
\text { et al. } \\
(1985)\end{array}$ \\
\hline \multirow[b]{2}{*}{ Ellipsoidal } & \multirow[b]{2}{*}{$\begin{array}{l}\text { Fricke } \\
(1924)\end{array}$} & & & & 0.5 & 0.65 & & & 0.5 \\
\hline & & & & & $\begin{array}{l}\text { Ferre } \\
\text { et al. } \\
\text { (1996) }\end{array}$ & $\begin{array}{l}\text { Roth } \\
\text { et al. } \\
(1990)\end{array}$ & & & \\
\hline \multirow{2}{*}{$\begin{array}{l}\text { Poly- } \\
\text { dispersed }\end{array}$} & \multirow{2}{*}{$\begin{array}{l}\text { Bruggeman } \\
\text { (1935) }\end{array}$} & & & & 0.5 & $-1.0 \sim 1.0$ & & & \\
\hline & & & & & $\begin{array}{l}\text { Malicki } \\
\text { et al. } \\
\text { (1996) }\end{array}$ & $\begin{array}{c}\text { Jacobsen\& } \\
\text { Schjonning } \\
\text { (1995) }\end{array}$ & & & \\
\hline \multirow[t]{15}{*}{$\begin{array}{l}\text { Flat disk } \\
\text { sphere } \\
\text { needle }\end{array}$} & \multirow[t]{15}{*}{$\begin{array}{l}\text { Sillers } \\
(1936)\end{array}$} & & & & 0.5 & $0.4 \sim 0.8$ & & & \\
\hline & & & & & & $\begin{array}{l}\text { Knoll } \\
(1996)\end{array}$ & & & \\
\hline & & & & & & $-1.0 \sim 1.0$ & & & \\
\hline & & & & & & $\begin{array}{c}\text { Yu } \\
\text { et al. } \\
\text { (1997) }\end{array}$ & & & \\
\hline & & & & & & $0.5 \sim 1.0$ & & & \\
\hline & & & & & & $\begin{array}{l}\text { Kellner } \\
\text { et al. } \\
\text { (2001) }\end{array}$ & & & \\
\hline & & & & & & $0.28 \sim 0.38$ & & & \\
\hline & & & & & & $\begin{array}{l}\text { Schaap } \\
\text { et al. } \\
(2003)\end{array}$ & & & \\
\hline & & & & & & $0.5 \sim 1.0$ & & & \\
\hline & & & & & & $\begin{array}{l}\text { Kowalsky } \\
\text { et al. } \\
\text { (2004) }\end{array}$ & & & \\
\hline & & & & & & 0.5 & & & \\
\hline & & & & & & $\begin{array}{l}\text { Robinson } \\
\text { et al. } \\
\text { (2005) }\end{array}$ & & & \\
\hline & & & & & & $0.5 \sim 1.0$ & & & \\
\hline & & & & & & $\begin{array}{l}\text { Mironov } \\
\text { et al. } \\
(2009)\end{array}$ & & & \\
\hline & & & & & & 0.5 & & & \\
\hline
\end{tabular}

Figure 2. Overview of the models used for computing the effective dielectric constant: micro-geometry models [3-9,50,51], dielectric mixing models [30,52], refractive mixing models $[31,33-46,53,54]$ and calibration models [47-49]; the numbers under each box indicate the value used for the exponent $\alpha$ in Equation (4); black boxes mark the two main mixing theories for the computation of the effective dielectric constant; the gray boxes indicate the most widely-used semi-empirical approaches in airborne/space-borne microwave remote sensing. These models act as benchmarks for our new model.

\subsection{Multi-Phase Dielectric Mixing Model}

The volumetric fractions $v_{j}$ in Equation (1) can be described by the soil porosity $p$ and volumetric fraction of water, $\mathrm{w}$, as proposed by Wang and Schmugge [52], 


$$
\varepsilon_{\text {eff }}=(1-p) \varepsilon_{\text {soil }}+\mathrm{w} \varepsilon_{\text {water }}+(\mathrm{p}-\mathrm{w}) \varepsilon_{\text {air }}
$$

Because the dielectric constant follows the superposition rule of polarizability (see Appendix A), this constant, and not the refractive index, is linearly proportional to the volume of the physical material. Therefore, the arithmetic average of the dielectric constant by volumes of soil water, of soil particles and of air as shown in Equation (5) is the preferred approach from a theoretical point of view.

The volumetric ratios of the main soil minerals $\mathrm{v}_{\text {sand }}, \mathrm{v}_{\text {silt }}$ and $\mathrm{v}_{\text {clay }}$ enable us to derive a sub-phase model for $\varepsilon_{\text {soil }}$ according to:

$$
\begin{gathered}
\varepsilon_{\text {soil }}=\mathrm{v}_{\text {sand }} \varepsilon_{\text {sand }}+\mathrm{v}_{\text {silt }} \varepsilon_{\text {silt }}+\mathrm{v}_{\text {clay }} \varepsilon_{\text {clay }} \\
\text { with } \mathrm{v}_{\text {sand }}+\mathrm{v}_{\text {silt }}+\mathrm{v}_{\text {clay }}=1
\end{gathered}
$$

The effective dielectric constant of water in the land surface is the arithmetic average of the dielectric constant of free and of bound water according to:

$$
\begin{gathered}
\varepsilon_{\text {water }}=\mathrm{v}_{\text {bound }} \varepsilon_{\text {bound }}+\mathrm{v}_{\text {free }} \varepsilon_{\text {free }} \\
\text { with } \mathrm{v}_{\text {bound }}+\mathrm{v}_{\text {free }}=1
\end{gathered}
$$

In contrast to the mineral component in the soil, the computation of the dielectric constant of soil water $\varepsilon_{\text {water }}$ is more challenging because $\mathrm{v}_{\text {bound }}$ and $\mathrm{v}_{\text {free }}$ are unknown and cannot be measured; these parameters can only be determined by comparisons of the measured refractive indices with simulated data.

Both the real and the imaginary parts of the complex dielectric constant now change in such a way with the soil water fraction $w$. For low values of $w$, when the dry soil particles become moist and $\mathrm{w}$ remains below the wilting point, the volumetric soil water content consists only of bound water, and thus, $\mathrm{v}_{\text {bound }}=1$ in Equation (9) and $\varepsilon_{\text {water }}=\varepsilon_{\text {bound }}$ in Equation (8). Then, Equation (5) becomes:

$$
\varepsilon_{\text {eff }}=(1-\mathrm{p}) \varepsilon_{\text {soil }}+\mathrm{w} \varepsilon_{\text {bound }}+(\mathrm{p}-\mathrm{w}) \varepsilon_{\text {air }} \text { for } \mathrm{w}<\mathrm{w}_{\mathrm{wp}}
$$

When $\mathrm{w}$ is larger than the wilting point $\mathrm{w}_{\mathrm{wp}}$, but remains smaller than the porosity $\mathrm{p}$, the dielectric constant of water in the soil is a composite of the dielectric constants of bound water and free water, both of which show very different values for the dielectric constant [55-57]. The dominant force of bound water is the charge of soil particles, which attracts water molecules and causes them to adhere to the surface of soil particles forming thin layers around the mineral particles (see also Figure 3). The presence of increasing amounts of water in the soil serves to thicken the thin layer of water molecules, which causes the van der Waals force between these molecules [58] to dominate due to the surface charges of the soil particles; as a result, the water is able to move freely. This transition point, the wilting point $\mathrm{w}_{\mathrm{wp}}$, depends on the size and the characteristic electric charge of the soil particle. Based on this phase transition, we can model $v_{\text {bound }}$ assuming a linear decrease with the total water increase for $\mathrm{w}_{\mathrm{wp}}<\mathrm{w}<\mathrm{p}$. This assumption of a linear relation can be expressed as:

$$
\mathrm{v}_{\text {bound }}=\mathrm{a}+\mathrm{bw}
$$

When the total soil water $\mathrm{w}$ increases from $\mathrm{w}_{\mathrm{wp}}$ to $\mathrm{p}, \mathrm{v}_{\mathrm{bound}}$ decreases from 1 and 0 . We thus get from the assumption of a linear relation:

$$
\mathrm{b}=-\frac{1}{\mathrm{p}-\mathrm{w}_{\mathrm{wp}}}
$$


and:

$$
\mathrm{a}=\frac{\mathrm{p}}{\mathrm{p}-\mathrm{w}_{\mathrm{wp}}}
$$

By substituting Equations (12) and (13) into Equation (11), we can write $\mathrm{v}_{\text {bound }}$ in relation to $\mathrm{w}_{\mathrm{wp}}$ as:

$$
\mathrm{v}_{\text {bound }}=\frac{\mathrm{p}-\mathrm{w}}{\mathrm{p}-\mathrm{w}_{\mathrm{wp}}}
$$

and then get according to the conservation law of Equation (9):

$$
\mathrm{v}_{\text {free }}=\frac{\mathrm{w}-\mathrm{w}_{\mathrm{wp}}}{\mathrm{p}-\mathrm{w}_{\mathrm{wp}}}
$$

Thus, we can calculate the effective dielectric constant $\varepsilon_{\text {eff }}$ in dependence of $\mathrm{w}$ by replacing the unknown $v_{\text {bound }}$ and $v_{\text {free }}$ in the equation for $\varepsilon_{w a t e r}$ with the known constants $w_{w p}, p, \varepsilon_{\text {free. }}$ In summary, we obtain as relation between $\varepsilon_{\text {eff }}$ and $\mathrm{w}$ :

$$
\begin{gathered}
\varepsilon_{\text {eff }}=(1-p) \varepsilon_{\text {soil }}+\mathrm{w}\left(\frac{\mathrm{p}-\mathrm{w}}{\mathrm{p}-\mathrm{w}_{\mathrm{wp}}} \varepsilon_{\text {bound }}+\frac{\mathrm{w}-\mathrm{w}_{\mathrm{wp}}}{\mathrm{p}-\mathrm{w}_{\mathrm{wp}}} \varepsilon_{\text {free }}\right)+(\mathrm{p}-\mathrm{w}) \varepsilon_{\text {air }} \\
\text { for } \mathrm{w}_{\mathrm{wp}}<\mathrm{w} \leq \mathrm{p}
\end{gathered}
$$

Next, we investigate the case $\mathrm{w}>\mathrm{p}$. After heavy precipitation, not all water infiltrates the soil medium quickly. In this case, we must consider standing water on top of the soil within the observed volume. With increasing $\mathrm{w}$, the fraction of standing water over the soil layer increases, and the fraction of saturated soil medium (free water and soil particles) decreases. We can express the measurable effective dielectric constant with:

$$
\varepsilon_{\text {eff }}=\mathrm{v}_{\text {saturated }}\left\{(1-\mathrm{p}) \varepsilon_{\text {soil }}+\mathrm{p} \varepsilon_{\text {free }}\right\}+\mathrm{v}_{\text {standing }} \varepsilon_{\text {free }} \text { for } \mathrm{w}>\mathrm{p}
$$

Similar to the derivation of Equation (14), the standing water fraction $\mathrm{v}_{\text {standing }}$ can be computed using the linear approximation proposed in Equation (11) between $\mathrm{v}_{\text {standing }}$ and $\mathrm{w}$. Then, we obtain:

$$
\mathrm{v}_{\text {standing }}=\frac{\mathrm{w}-\mathrm{p}}{1-\mathrm{p}}
$$

and:

$$
\mathrm{v}_{\text {saturated }}=\frac{1-\mathrm{w}}{1-\mathrm{p}}
$$

We see from Equation (18) that if $\mathrm{w}=\mathrm{p}$, then $\mathrm{v}_{\text {standing }}=0$. If $\mathrm{w}=1$, then $\mathrm{v}_{\text {standing }}=1$. Equation (19) shows that if $\mathrm{w}=\mathrm{p}$, then $\mathrm{v}_{\text {saturated }}=1$; if $\mathrm{w}=1$, then $\mathrm{v}_{\text {saturated }}=0$. Equation (17) is thus equivalent to:

$$
\varepsilon_{\text {eff }}=(1-\mathrm{w}) \varepsilon_{\text {soil }}+\mathrm{w} \varepsilon_{\text {free }} \text { for } \mathrm{w}>\mathrm{p}
$$

It is interesting to note that the effective dielectric constant of wet soil with $w>p$ can simply be calculated from $\varepsilon_{\text {soil }}, \varepsilon_{\text {free }}$ and the measured $\mathrm{w}$ regardless of the wilting point and porosity.

The distinct dielectric properties of bound water and free water cause the effective dielectric constant of wet soil (Figure $3 b$ ) to become a nonlinear function of $w$ with three domains according to Equations (10), (16) and (20), the boundaries of which are given by $w_{w p}$ and $p$, as shown in Figure 4. 
a) $w \leq w_{w p}$
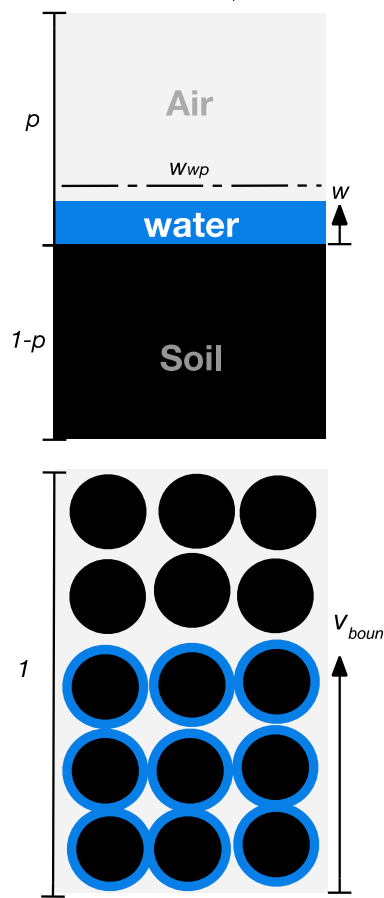

Dry
soil b) $w_{w p}<w \leq p$
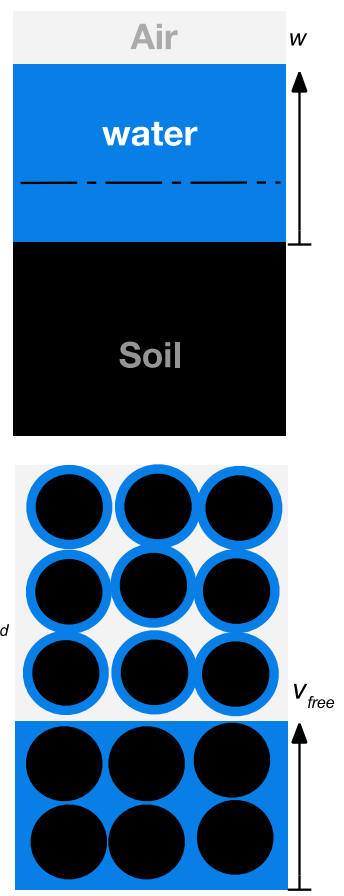

Free water

c) $p<w$
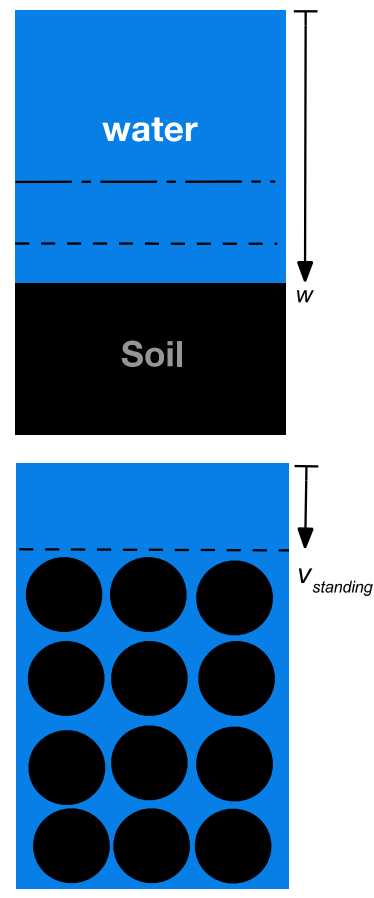
Standing

Figure 3. Illustration of the rescaling process for the volumetric fractions in moist soil. (a) Total soil water content $\mathrm{w}$ is smaller than the wilting point $\mathrm{w}_{\mathrm{wp}}$. Here, only bound water is present; (b) $\mathrm{w}$ greater than $\mathrm{w}_{\mathrm{wp}}$, but smaller than the soil porosity $\mathrm{p}$. Part of the water is bound and part is free; (c) w greater than $\mathrm{p}$. There is free water inside the soil and standing water above the soil, but no bound water in our mixing model. The dielectric constant of free and standing water is the same.

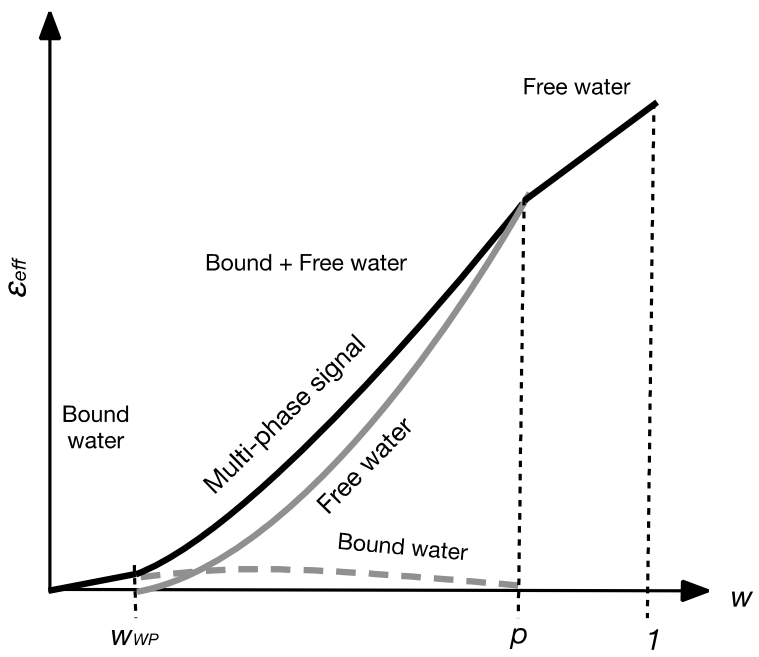

Figure 4. Multiphase behavior of the effective dielectric constant $\varepsilon_{\text {eff }}$ for different values of the soil water fraction w according to the new approach of Equations (10), (16) and (20), where $\mathrm{w}_{\mathrm{wp}}$ is the wilting point and $\mathrm{p}$ is the porosity, both of which are specific parameters for a given soil texture. The gray solid and dotted curves represent the free and bound water contributions, $\mathrm{w} \mathrm{v}_{\text {free }} \varepsilon_{\text {free }}$ and $\mathrm{W} \mathrm{v}_{\text {bound }} \varepsilon_{\text {bound }}$ to $\varepsilon_{\text {eff }}$, respectively. 
For the computation of effective conductivity, it is popular to apply the Bruggeman model $[6,59]$ and Maxwell Garnett model $[5,60]$ similarly to the calculation of the effective dielectric constant. However, in several studies, the computation of the effective conductivity is based on the arithmetic average of the volumetric mixing ratio [2,61,62]. Similar to Equations (10), (16) and (20), we can develop a new multiphase mixing model also for the effective conductivity and get:

$$
\begin{gathered}
\sigma_{\text {eff }}=(1-\mathrm{p}) \sigma_{\text {soil }}+\mathrm{w}\left(\frac{\mathrm{w}}{\mathrm{w}_{\mathrm{wp}}} \sigma_{\text {bound }}+\widetilde{\sigma}_{\text {salt }}\right)+(\mathrm{p}-\mathrm{w}) \sigma_{\text {air }} \\
\text { for } \mathrm{w} \leq \mathrm{w}_{\mathrm{wp}} \\
\sigma_{\text {eff }}=(1-\mathrm{p}) \sigma_{\text {soil }}+\mathrm{w}\left(\frac{\mathrm{p}-\mathrm{w}}{\mathrm{p}-\mathrm{w}_{\mathrm{wp}}} \sigma_{\text {bound }}+\frac{\mathrm{w}-\mathrm{w}_{\mathrm{wp}}}{\mathrm{p}-\mathrm{w}_{\mathrm{wp}}} \sigma_{\text {free }}+\widetilde{\sigma}_{\text {salt }}\right)+(\mathrm{p}-\mathrm{w}) \sigma_{\text {air }} \\
\text { for } \mathrm{w}_{\mathrm{wp}}<\mathrm{w} \leq \mathrm{p}
\end{gathered}
$$

and:

$$
\sigma_{\text {eff }}=(1-\mathrm{w}) \sigma_{\text {soil }}+\mathrm{w}\left(\sigma_{\text {free }}+\widetilde{\sigma}_{\text {salt }}\right) \text { for } \mathrm{w}>\mathrm{p}
$$

The further derivation of $\sigma_{\text {eff }}$, which consists of soil $\sigma_{\text {soil }}$, bound water $\sigma_{\text {bound }}$, free water $\sigma_{\text {free, }}$ salinity $\widetilde{\sigma}_{\text {salt }}$ and air $\sigma_{\text {air }}$, is provided in Appendix B.

The complex dielectric constant $\varepsilon^{*}$ consists of the effective polarization term $\varepsilon^{\prime}$ eff as the real part, the effective dielectric loss $\varepsilon^{\prime \prime}$ eff and effective conductivity $\sigma_{\text {eff }}$ according to:

$$
\varepsilon^{*}=\varepsilon_{\text {eff }}^{\prime}+\mathrm{i}\left(\varepsilon^{\prime \prime} \text { eff }+\frac{\sigma_{\text {eff }}}{\omega \varepsilon_{\mathrm{o}}}\right)
$$

For $\mathrm{w}_{\mathrm{wp}}<\mathrm{w}<\mathrm{p}$ and $\mathrm{p}<\mathrm{w}$, the effective dielectric constants for both the real part $\varepsilon^{\prime}$ eff and imaginary part $\varepsilon^{\prime \prime}$ eff are computed by Equations (10), (16) and (20).

\subsection{Frequency-Dependent Dielectric Relaxation Model}

The frequency-dependent dielectric constant for free and bound water can be derived by Debye's relaxation formula, substituting:

$$
\begin{gathered}
\varepsilon_{\text {free,bound }}^{\prime}=\varepsilon_{\text {free,bound }}^{\min }+\frac{\varepsilon_{\text {free,bound }}^{\max }-\varepsilon^{\min }}{1+\omega^{2} \tau_{\text {free,bound }}^{2}} \\
\mathcal{E}^{\prime \prime} \text { free,bound }=\frac{\omega \tau_{\text {free,bound }}\left(\varepsilon_{\text {free, bound }}^{\max }-\varepsilon^{\min }\right)}{1+\omega^{2} \tau_{\text {free,bound }}^{2}} \\
\varepsilon^{\min }=4.9 \\
\varepsilon_{\text {free }}^{\max }=\left(88.045-0.4147 \mathrm{~T}+6.295 \times 10^{-4} \mathrm{~T}^{2}+1.075 \times 10^{-5} \mathrm{~T}^{3}\right) \cdot \mathrm{a} \mathrm{ST} \\
\mathrm{aST}_{\mathrm{ST}}=1+1.613 \times 10^{-3} \mathrm{~S} \times \mathrm{T}-3.656 \times 10^{-3} \mathrm{~S}+3.21 \times 10^{-5} \mathrm{~S}^{2}-4.232 \times 10^{-7} \mathrm{~S}^{3} \\
\tau_{\text {free }}=\left(1.1109 \times 10^{-10}+3.824 \times 10^{-12} \mathrm{~T}+6.938 \times 10^{-14} \mathrm{~T}^{2}-5.096\right. \\
\left.\mathrm{b}_{\mathrm{ST}}=1+2.282 \times 10^{-16} \mathrm{~T}^{3}\right) \frac{\mathrm{b}_{\mathrm{ST}}}{2 \pi} \\
\end{gathered}
$$

into Equations (10), (16) and (20). $\varepsilon_{\text {free }}^{\max }$ is the static dielectric constant of free water computed according to Klein and Swift [63], and $\varepsilon_{\text {free }}^{\min }$ is obtained according to Lane and Saxton [64]. $\tau_{\text {free }}$ is the dielectric relaxation time for free water given in Equation (30) based on [65]. T and $S$ used in these equations are soil temperature $\left({ }^{\circ} \mathrm{C}\right)$ and salinity $(\%)$. The bound water relaxation is frequency-dependent (omega in Equations (25) and (26)). It also changes according to soil texture [66,67], the variation of which is 
reflected in the bound water relaxation model (25) and (26) by applying a linear equation varying with $\mathrm{v}_{\text {clay }}$ to the estimation of the parameters $\varepsilon_{\text {bound }}^{\max }$ as shown in (32):

$$
\varepsilon_{\text {bound }}^{\max }=\mathrm{a} \cdot \mathrm{v}_{\text {clay }}+\mathrm{b}
$$

with the relaxation time of the bound water (33):

$$
\tau_{\text {bound }}=10^{-11_{S}}
$$

The model for the effective dielectric constant for the bound water (25) and (26) does depend on wavelength and soil texture, and the optimal fitting parameters, a and b, will be provided in Section 3 .

\subsection{Bulk Dielectric Mixing Model}

For the dielectric constant of a three-dimensional medium, its geometrical structure and thickness are relevant. For example, the effective value of the polarization density $\mathrm{P}$ should be reduced by $1 / 3$, a number termed the depolarization factor for the spherical shape [3]. The non-spherical shape effect of soil particles in saturated and unsaturated porous media was reviewed by [68]. Recent studies showed that by increasing the thickness of a medium, the effective value of the dielectric constant decreases [44,69-71]. In short, a reduction of the bulk dielectric constant compared to the flat 2D dielectric constant is attributable to both the 3D microgeometry and the thickness of the medium. In the following, we idealize the complex morphology of the land surface properties found in nature and consider the soil as isotropic. Thus, we focus on the damping effect within the sampling depth, such as the penetration depth of TDR or GPR or an emission depth of SMOS [72] or SMAP [73].

The sampling depth describes that part of the medium that is responsible for the surface emission; thus, the dielectric constant of this layer is relevant [74] because only the energy emitted from it is detected by remote sensing instruments [75]. In other words, the signal detected over a surface is not only related to the arithmetic average of the dielectric constant of the soil properties, but also determined by the sampling depth. With increasing depth, the contribution of the signal from that depth to the average signal intensity becomes smaller and smaller. Without considering attenuation, the quantification of soil moisture content from the surface emission alone is underestimated.

The computation of the surface emission from the sampling depth is related to a nonlinear weighting function, such as a decaying function with depth [76]. Wilheit [77] proposed a layered model for the electric field in the distinct interface between air (free space) and the soil surface. For each layer, the surface polarization density is related to the surface effective susceptibility $\chi_{\text {eff }}$ and the electric field $\mathrm{E}(\mathrm{z})$ in that layer according to:

$$
P_{\text {eff }}(z)=\varepsilon_{0} \chi_{\text {eff }} E(z)
$$

If the medium is homogenous, Beer-Lambert's law yields:

$$
\mathrm{E}(\mathrm{z})=\mathrm{E}(0) \exp \left(-\frac{\mathrm{z}}{2 \delta_{\text {eff }}}\right)
$$

with the effective penetration depth $\delta_{\text {eff }}$, which depends on the imaginary part of the effective refractive index. By integrating the surface polarization density $\mathrm{P}_{\text {eff }}(\mathrm{z})$ up to the penetration depth $\mathrm{z}$, we obtain:

$$
\mathrm{P}_{\mathrm{eff}}^{3 \mathrm{D}}=\varepsilon_{0} \chi_{\mathrm{eff}} \mathrm{E}(0) \frac{2 \delta_{\mathrm{eff}}}{\mathrm{z}}\left(1-\exp \left(-\frac{\mathrm{z}}{2 \delta_{\mathrm{eff}}}\right)\right)
$$

The same can also be written with the effective electric susceptibility of a bulk substance $\chi_{\text {eff }}^{3 D}$ as:

$$
\mathrm{P}_{\mathrm{eff}}^{3 \mathrm{D}}=\varepsilon_{0} \chi_{\mathrm{eff}}^{3 \mathrm{D}} \mathrm{E}(0)
$$


Therefore, we get:

$$
\chi_{\text {eff }}^{3 \mathrm{D}}=\chi_{\text {eff }} \mathrm{H}_{\mathrm{z}}
$$

where:

$$
\mathrm{H}_{\mathrm{z}}=\frac{2 \delta_{\text {eff }}}{\mathrm{z}}\left(1-\exp \left(-\frac{\mathrm{z}}{2 \delta_{\text {eff }}}\right)\right)
$$

By inserting the attenuation factor $\mathrm{H}_{\mathrm{z}}$ into Equation (24), we can obtain the real part of the 3D complex effective dielectric constant according to:

$$
\varepsilon_{\text {eff }}^{\prime 3 \mathrm{D}}=\left(\varepsilon^{\prime}{ }_{\text {eff }}-1\right) \mathrm{H}_{\mathrm{z}}+1
$$

and for the imaginary part:

$$
\varepsilon^{\prime \prime}{ }_{\text {eff }}^{3 \mathrm{D}}=\varepsilon^{\prime \prime}{ }_{\text {eff }} \mathrm{H}_{\mathrm{z}}
$$

Furthermore, we get for the effective conductivity:

$$
\sigma_{\text {eff }}^{3 \mathrm{D}}=\sigma_{\text {eff }} \mathrm{H}_{\mathrm{z}}
$$

If the sampling of the soil layer is obtained with penetration depth $\delta_{\text {eff }}$, one needs to insert $\delta_{\text {eff }}$ for $\mathrm{z}$ in Equation (39), and $\mathrm{H}_{\mathrm{z}}$ becomes the constant $\mathrm{H}_{\delta}$ (independent of wavelength and extinction coefficient)

$$
\mathrm{H}_{\delta}=2(1-\exp (-0.5)) \approx 0.8
$$

As discussed later, we found that this simple approach of a constant damping factor for the three-dimensional nature of the soil provides excellent results compared to experimental data.

\subsection{Comparison with Other Approaches}

In the following, we compare the general expression of the dielectric mixing and refractive mixing model:

$$
\begin{gathered}
\varepsilon_{\text {eff }}=a \varepsilon_{\text {soil }}+b \varepsilon_{\text {bound }}+c \varepsilon_{\text {free }}+d \varepsilon_{\text {air }} \\
\varepsilon_{\text {eff }}=\left(a \varepsilon_{\text {soil }}^{\alpha}+b \varepsilon_{\text {soil }}^{\alpha}+c \varepsilon_{\text {soil }}^{\alpha}+d \varepsilon_{\text {soil }}^{\alpha}\right)^{1 / \alpha} \\
\mathrm{n}_{\text {eff }}=\mathrm{an}_{\text {soil }}+b n_{\text {bound }}+\mathrm{cn}_{\text {free }}+d n_{\text {air }}
\end{gathered}
$$

where $\mathrm{a}, \mathrm{b}, \mathrm{c}$ and $\mathrm{d}$ are the volumetric mixing ratios of each phase, which is a function of soil properties and empirical parameters, as listed in Table 1. To ensure correspondence between the simulation of the effective dielectric constant and the actual measurements, Wang and Schmugge [53] proposed the transition moisture $\mathrm{w}_{\mathrm{t}}$, which is larger than the wilting point. If $\mathrm{w}_{\mathrm{t}}$ is utilized to compute the bound water fraction $b$ and free water fraction c according to Equations (14) and (15), b increases and c decreases, thereby causing an underestimation of the effective dielectric constant. Therefore, the use of $\mathrm{w}_{\mathrm{t}}$ requires the empirical parameter $\mathrm{Y}$ to obtain a fit between the predicted and measured effective dielectric constants. Dobson et al. [34] suggested for $\alpha$ in Equation (45) an empirical value of 0.65 and $\mathrm{w}^{\beta}$ with $\beta$, which is a function of soil texture for $\mathrm{c}$. This choice leads to a total volumetric ratio larger than 1 in some cases, which is of course unrealistic. In the approach of Mironov et al. [53,78], a negative volumetric ratio appears in $\mathrm{d}$, the volumetric mixing ration of air, in some cases. Moreover, the free water dielectric constant reaches quite high values of up to 100 and becomes furthermore an empirical function of the clay-mixing ratio, which seems unrealistic. In addition, this approach does not use the porosity information in the refractive mixing model (see Equation (46)) and, thus, does not show a connection between the soil texture and the effective dielectric constant, which seems unrealistic, as well. Therefore, while previous models simulate measured data experimentally with satisfactory accuracy, these models have to assume unphysical parameters in order to achieve this, which is unsatisfactory from a theoretical point of view. 
Table 1. List of volumetric mixing ratios in the general expression of the dielectric and refractive mixing formulas.

\begin{tabular}{ccccccc}
\hline & & $\mathbf{a}$ & $\mathbf{b}$ & $\mathbf{c}$ & $\mathbf{d}$ & $\mathbf{a}+\mathbf{b}+\mathbf{c}+\mathbf{d}$ \\
\hline \multirow{4}{*}{$\mathrm{w} \leq \mathrm{w}_{\mathrm{wp}}$} & Wang and Schmugge [52] & $1-\mathrm{p}$ & $\frac{\mathrm{w}_{\mathrm{t}}-\mathrm{w} \gamma}{\mathrm{w}_{\mathrm{t}}} \mathrm{w}$ & $\frac{\mathrm{w} \gamma}{\mathrm{w}_{\mathrm{t}}} \mathrm{w}$ & $\mathrm{p}-\mathrm{w}$ & 1 \\
& Dobson et al. [34] & $1-\mathrm{p}$ & 0 & $\mathrm{w}^{\beta}$ & $\mathrm{p}-\mathrm{w}$ & $>1$ \\
& Mironov et al. [53,78] & 1 & $\mathrm{w}$ & 0 & $-\mathrm{w}$ & 1 \\
& Proposed model & $1-\mathrm{p}$ & $\mathrm{w}$ & 0 & $\mathrm{p}-\mathrm{w}$ & 1 \\
\hline \multirow{3}{*}{$\mathrm{w}_{\mathrm{wp}}<\mathrm{w} \leq \mathrm{p}$} & Wang and Schmugge [52] & $1-\mathrm{p}$ & $(1-\gamma) \mathrm{w}$ & $\mathrm{w} \gamma$ & $\mathrm{p}-\mathrm{w}$ & 1 \\
& Dobson et al. [34] & $1-\mathrm{p}$ & 0 & $\mathrm{w}^{\beta}$ & $\mathrm{p}-\mathrm{w}$ & $>1$ \\
& Mironov et al. [53,78] & 1 & $\mathrm{w}_{\mathrm{wp}}$ & $\mathrm{w}-\mathrm{w}_{\mathrm{wp}}$ & $-\mathrm{w}$ & 1 \\
& Proposed model & $1-\mathrm{p}$ & $\frac{\mathrm{p}-\mathrm{w}}{\mathrm{p}-\mathrm{w}_{\mathrm{wp}} \mathrm{w}}$ & $\frac{\mathrm{w}-\mathrm{w}_{\mathrm{wp}}}{\mathrm{p}-\mathrm{w}_{\mathrm{wp}}}$ & $\mathrm{p}-\mathrm{w}$ & 1 \\
\hline \multirow{5}{*}{$\mathrm{p}<\mathrm{w}$} & Wang and Schmugge [52] & - & - & - & - & - \\
& Dobson et al. [34] & - & - & - & - & - \\
& Mironov et al. [53,78] & - & - & - & - & - \\
\hline & Proposed model & $1-\mathrm{w}$ & 0 & $\mathrm{w}$ & 0 & 1 \\
\hline
\end{tabular}

The following equations were used: (44) for Wang and Schmugge and this paper (Park et al.), (45) for Dobson et al., and (46) for Mironov et al.

We also investigated a simple calibration model based on the linear relationship between the refractive index $\sqrt{\varepsilon_{\text {eff }}}$ and the soil water content $\mathrm{w}$ :

$$
\mathrm{w}=\mathrm{a} \sqrt{\varepsilon_{\mathrm{eff}}}+\mathrm{b}
$$

which is widely utilized for GPR applications, where $a=0.1168, b=-0.19$ in [36], and for TDR applications, where $\mathrm{a}=0.1138, \mathrm{~b}=-0.1758$ in [35], $\mathrm{a}=0.1181, \mathrm{~b}=-0.1841$ in [37], and $\mathrm{a}=0.14, \mathrm{~b}=-0.2$ in [38]. This approach has been suggested as the refractive-index mixing approach, which only considers the soil water content. We can express the effective dielectric constant $\varepsilon_{\text {eff }}$ as a polynomial function of the soil water content $\mathrm{w}$ according to:

$$
\varepsilon_{\text {eff }}=\frac{1}{a^{2}} w^{2}-\frac{2 b}{a^{2}} w+\frac{b^{2}}{a^{2}}
$$

Equation (48) needs various empirical fitting parameters for different soil textures. This quadratic polynomial calibration model was also proposed for microwave remote sensing by Hallikainen [50] with:

$$
\varepsilon_{\text {eff }}=\left(c_{0}+c_{1} v_{\text {sand }}+c_{2} v_{\text {clay }}\right) w^{2}+\left(b_{0}+b_{1} v_{\text {sand }}+b_{2} v_{\text {clay }}\right) w+\left(a_{0}+a_{1} v_{\text {sand }}+a_{2} v_{\text {clay }}\right)
$$

Compared to Equation (48), Equation (49) is not only a function of the soil water content w, but also of the soil texture. Therefore, the model is able to simulate the effective dielectric constant of various soil textures with good agreement to the measurements; however, it requires quite a large number of nine empirical fitting parameters.

$$
\varepsilon_{\text {eff }}=\frac{\varepsilon_{\text {free }}-\varepsilon_{\text {bound }}}{p-w_{w p}} w^{2}+\frac{p \varepsilon_{\text {bound }}-w_{w p} \varepsilon_{\text {free }}}{p-w_{w p}} w+(1-p) \varepsilon_{\text {soil }}+(p-w) \varepsilon_{\text {air }}
$$

One can see from in Equation (50), which is actually the same formula of Equation (16), that the fitting parameters of the empirical polynomial models of Equations (48) and (49) are a combination of the dielectric constants $\varepsilon_{\text {bound }}$ and $\varepsilon_{\text {free }}$ and the physical soil properties $\mathrm{w}_{\mathrm{wp}}$ and $\mathrm{p}$. As a result, one can estimate the soil water content from the dielectric measurements without the need for empirical parameters or different calibrations for different soil conditions; the only unknown parameter, which cannot be resolved, is $\varepsilon_{\text {bound }}$. However, this single parameter can be determined by comparing the mixing model with observations. 
In this study, we compare our model with above models including a modified Mironov model. The model of Mironov et al. (2009) is the originally proposed refractive mixing model [53,78], which uses a static dielectric constant of free water $\left(\varepsilon_{\text {free }}^{\max }\right)$ of 100 in Equations (25) and (26). In contrast to this, "Mironov et al. (2009), modified" is the model of Mironov et al. (2009) modified with $\varepsilon_{\text {free }}^{\max }=80$, which is the same value as used in all other approaches. This value can either be measured [79] or modeled [63] at $20^{\circ} \mathrm{C}$ with the surface pressure level of $0.1 \mathrm{MPa}$ (see also Equations (25) and (26)). The performance scores of these models are evaluated with:

$$
\text { Absolute RMSE }=\sqrt{\frac{1}{n} \sum_{t=1}^{n}\left(\varepsilon_{t, \text { eff }}-\varepsilon_{t, \text { measured }}\right)^{2}}
$$

and:

$$
\text { Relative RMSE }=\text { Absolute RMSE } \frac{100 \%}{\frac{1}{n} \sum_{\mathrm{t}=1}^{\mathrm{n}} \varepsilon_{\mathrm{t}, \text { measured }}}
$$

\subsection{Summary of New Model}

In summary, we can calculate the wave-dependent complex effective dielectric constant for various soil textures using the following formulas:

for $\mathrm{w} \leq \mathrm{w}_{\mathrm{wp}}$ :

$$
\begin{aligned}
& \varepsilon_{\text {eff }}^{\prime}=0.8\left((1-\mathrm{p})\left(\mathrm{v}_{\text {sand }} \varepsilon^{\prime}{ }_{\text {sand }}+\mathrm{v}_{\text {silt }} \varepsilon_{\text {silt }}^{\prime}+\mathrm{v}_{\text {clay }} \varepsilon_{\text {clay }}^{\prime}\right)+\mathrm{w} \varepsilon_{\text {bound }}^{\prime}+(\mathrm{p}-\mathrm{w}) \varepsilon_{\text {air }}^{\prime}\right)
\end{aligned}
$$

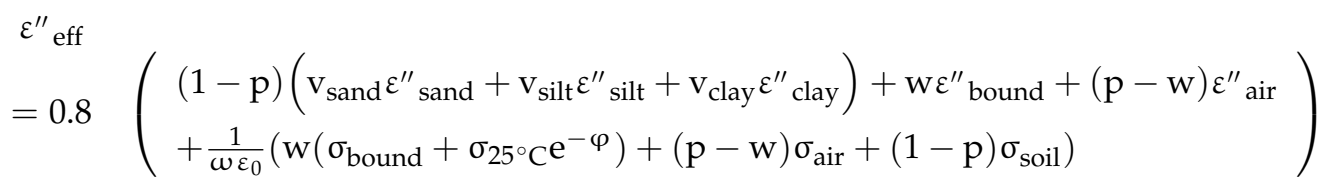

for $\mathrm{w}_{\mathrm{wp}}<\mathrm{w} \leq \mathrm{p}$ :

$$
\begin{aligned}
& \varepsilon_{\text {eff }}^{\prime}=0.8\left((1-\mathrm{p})\left(\mathrm{v}_{\text {sand }} \varepsilon_{\text {sand }}^{\prime}+\mathrm{v}_{\text {silt }} \varepsilon_{\text {silt }}^{\prime}+\mathrm{v}_{\text {clay }} \varepsilon_{\text {clay }}^{\prime}\right)\right. \\
& \left.+\mathrm{w}\left(\frac{\mathrm{p}-\mathrm{w}}{\mathrm{p}-\mathrm{w}_{\mathrm{wp}}} \varepsilon_{\text {bound }}^{\prime}+\frac{\mathrm{w}-\mathrm{w}_{\mathrm{wp}}}{\mathrm{p}-\mathrm{w}_{\mathrm{wp}}} \varepsilon_{\text {free }}^{\prime}\right)+(\mathrm{p}-\mathrm{w}) \varepsilon_{\text {air }}^{\prime}\right) \\
& \varepsilon^{\prime \prime} \text { eff }=0.8\left((1-\mathrm{p})\left(\mathrm{v}_{\text {sand }} \varepsilon^{\prime \prime}{ }_{\text {sand }}+\mathrm{v}_{\text {silt }} \varepsilon^{\prime \prime}{ }_{\text {silt }}+\mathrm{v}_{\text {clay }} \varepsilon^{\prime \prime} \text { clay }\right)\right. \\
& +\mathrm{w}\left(\frac{\mathrm{p}-\mathrm{w}}{\mathrm{p}-\mathrm{w}_{\mathrm{wp}}} \varepsilon^{\prime \prime} \text { bound }+\frac{\mathrm{w}-\mathrm{w}_{\mathrm{wp}}}{\mathrm{p}-\mathrm{w}_{\mathrm{wp}}} \varepsilon^{\prime \prime} \text { free }\right)+(\mathrm{p}-\mathrm{w}) \varepsilon^{\prime \prime} \text { air } \\
& +\frac{1}{\omega \varepsilon_{0}}\left(\mathrm{w}\left(\frac{\mathrm{p}-\mathrm{w}}{\mathrm{p}-\mathrm{w}_{\mathrm{wp}}} \sigma_{\text {bound }}+\frac{\mathrm{w}-\mathrm{w}_{\mathrm{wp}}}{\mathrm{p}-\mathrm{w}_{\mathrm{wp}}} \sigma_{\text {free }}+\sigma_{25^{\circ} \mathrm{C}} \mathrm{e}^{-\varphi}\right)+(1\right. \\
& \left.\left.-\mathrm{p}) \sigma_{\text {soil }}+(\mathrm{p}-\mathrm{w}) \sigma_{\text {air }}\right)\right)
\end{aligned}
$$

and for $\mathrm{p}<\mathrm{w}$ :

$$
\begin{aligned}
& \varepsilon_{\text {eff }}^{\prime}=0.8\left((1-\mathrm{w})\left(\mathrm{v}_{\text {sand }} \varepsilon_{\text {sand }}^{\prime}+\mathrm{v}_{\text {silt }} \varepsilon_{\text {silt }}^{\prime}+\mathrm{v}_{\text {clay }} \varepsilon_{\text {clay }}^{\prime}\right)+\mathrm{w} \varepsilon_{\text {free }}^{\prime}\right) \\
& \mathcal{E}^{\prime \prime} \text { eff }=0.8\left((1-\mathrm{w})\left(\mathrm{v}_{\text {sand }} \varepsilon^{\prime \prime}{ }_{\text {sand }}+\mathrm{v}_{\text {silt }} \mathcal{E}^{\prime \prime} \text { silt }+\mathrm{v}_{\text {clay }} \mathcal{\varepsilon}^{\prime \prime} \text { clay }\right)+\mathrm{w} \mathcal{E}^{\prime \prime}\right. \text { free } \\
& \left.+\frac{1}{\omega \varepsilon_{0}}\left(\mathrm{w}\left(\sigma_{\text {free }}+\sigma_{25^{\circ} \mathrm{C}} \mathrm{e}^{-\varphi}\right)+(1-\mathrm{w}) \sigma_{\text {soil }}\right)\right)
\end{aligned}
$$

\subsection{Experimental Reference Data}

In the prediction of the dielectric constant, the model proposed in this study requires the direct gravimetric measurement of soil moisture, temperature, volumetric mixing ratio of clay, silt, sand and salinity measurements. The fact that the organic material volume information is not taken into account 
is likely to be an error factor in our model. Unlike soil samples (A-I in Table 2), soil water contents measured in radio waves (J-X in Table 2) do not contain salinity information. Although it is obviously an error factor in the imaginary part of the dielectric constant, the verification was performed with the dielectric measurements in the range of the radio wave band because it is not a significant error factor in the computation of the real parts of the dielectric constant.

The verification of the dielectric constants predicted by the model with the observed soil parameters as an input is carried out based on the dielectric constant measured by microwave probes or TDR. We used the Roth et al. data [48] as shown in Table 2 on the assumption that instrumental error was minimized. The total number of samples was verified with a total of 131 point measurements (69 from L-, 41 from C-, 21 from K-bands) at 9 sample sites in the microwave and 148 point measurements at 15 sample sites in $30-\mathrm{MHz}$ measurements. Table 2 shows the values of the volumetric mixing ratio of soil texture for $\mathrm{v}_{\text {sand }}, \mathrm{v}_{\text {silt }}$ and $\mathrm{v}_{\text {clay }}$, salinity and temperature. In order to find proper values for the wilting point $\mathrm{w}_{\mathrm{wp}}$ and porosity $\mathrm{p}$, we first identify the soil texture by matching the measured sand, silt and clay mixing ratios of the references to the USDA (United States Department of Agriculture) soil texture classification. According to the identified soil texture, we obtained $\mathrm{w}_{\mathrm{wp}}$ and $\mathrm{p}$ from the input table for the soil parameters in NOAH-MP (Noah land surface model with multi-parameterization options) (Niu et al. 2011b), which are based on the STATSGO (State Soil Geographic) Data Base (Soil Survey Staff). Table 3 lists the values for $\mathrm{w}_{\mathrm{wp}}$ and $\mathrm{p}$ following this approach for different soil textures. $\varepsilon^{\prime}$ bound, $\varepsilon^{\prime}$ free; $\varepsilon^{\prime \prime}$ bound and $\varepsilon^{\prime \prime}$ free are calculated with Equations (25) and (26). $\sigma_{\text {bound }}$ and $\sigma_{\text {free }}$ are calculated with Equations (A13) and (A14), respectively, using Table 4; $\sigma_{25^{\circ} \mathrm{C}}$ and $\varphi$ are calculated with Equations (A10) and (A11), respectively, using the salinity and temperature given in Table 2; $\sigma_{\text {soil }}$ follows Equation (A5) with the data of Table 4 and $\sigma_{\text {air }}=0$.

Table 2. Volumetric mixing ratio of soil texture, salinity and temperature from the references.

\begin{tabular}{|c|c|c|c|c|c|c|c|}
\hline Soil Texture & Sample & Reference & $\begin{array}{c}\mathbf{v}_{\text {sand }} \\
\left(\mathrm{cm}^{3} / \mathrm{cm}^{3}\right)\end{array}$ & $\begin{array}{c}v_{\text {silt }} \\
\left(\mathrm{cm}^{3} / \mathrm{cm}^{3}\right)\end{array}$ & $\begin{array}{c}v_{\text {clay }} \\
\left(\mathrm{cm}^{3} / \mathrm{cm}^{3}\right)\end{array}$ & Salinity $(\%)$ & Temperature $\left({ }^{\circ} \mathrm{C}\right)$ \\
\hline Sand1 & A & {$[78,80]$} & 1.0 & 0.0 & 0.0 & 0.000 & 20 \\
\hline Sandy loam1 & D & [80] & 0.55 & 0.32 & 0.13 & 0.600 * & 20 \\
\hline Sandy loam2 & E & {$[34,50]$} & 0.515 & 0.350 & 0.135 & 0.685 & 22 \\
\hline Silt loam & $\mathbf{F}$ & [81] & 0.172 & 0.638 & 0.190 & 0.738 & 23 \\
\hline Silt1 & B & [80] & 0.0 & 0.93 & 0.07 & $0.600 *$ & 20 \\
\hline Silt2 & C & [80] & 0.040 & 0.89 & 0.07 & $0.600 *$ & 20 \\
\hline Silty clay loam & G & {$[78,80]$} & 0.02 & 0.64 & 0.34 & $0.000 *$ & 20 \\
\hline Silty clay & $\mathbf{H}$ & [34] & 0.05 & 0.476 & 0.474 & 0.600 & 20 \\
\hline Clay1 & I & [53] & 0.03 & 0.35 & 0.62 & 0.100 & 20 \\
\hline Clay2 & $\mathbf{J}$ & [48] & 0.04 & 0.16 & 0.80 & - & - \\
\hline Clay3 & K & [48] & 0.04 & 0.16 & 0.80 & - & - \\
\hline Sand2 & $\mathbf{L}$ & [48] & 0.88 & 0.10 & 0.02 & - & - \\
\hline Silty clay & $\mathbf{M}$ & [48] & 0.02 & 0.52 & 0.46 & - & - \\
\hline Loam & $\mathbf{N}$ & [48] & 0.36 & 0.31 & 0.23 & - & - \\
\hline Clay loam & $\mathbf{O}$ & [48] & 0.35 & 0.31 & 0.34 & - & - \\
\hline Silt loam & $\mathbf{P}$ & [48] & 0.02 & 0.75 & 0.23 & - & - \\
\hline
\end{tabular}


Table 2. Cont.

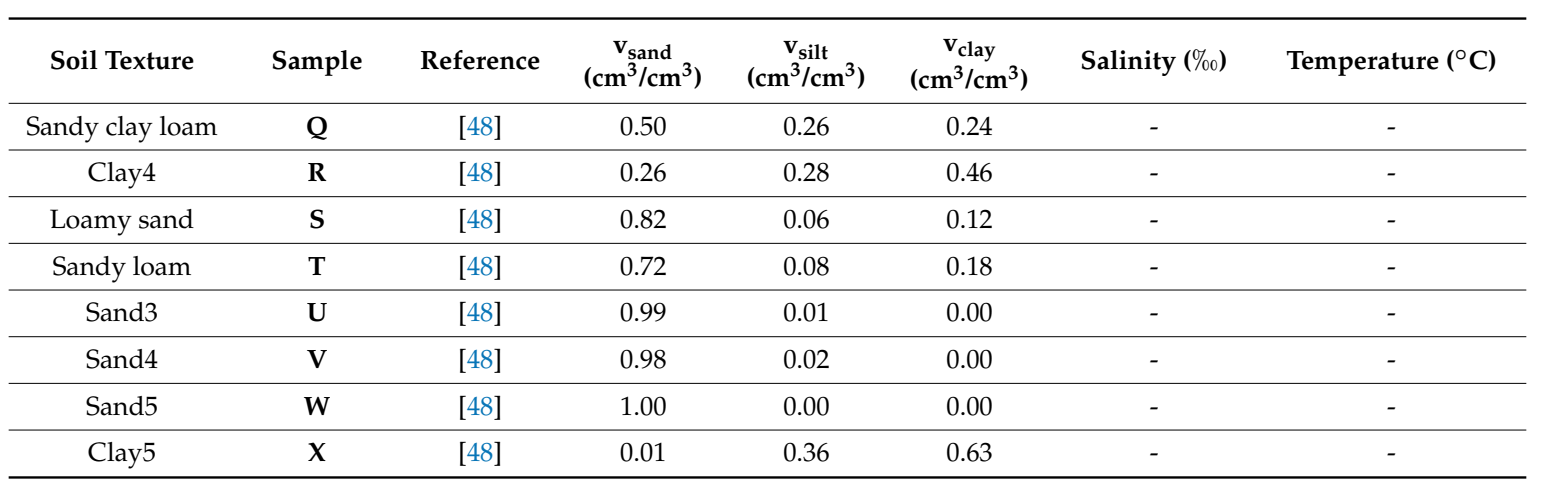

Soil mixing ratios in [78] and [80] are obtained by weight. Because the specific gravity of soil minerals is almost the same [80], their weight percentages are equivalently utilized as the volumetric mixing ratio and the values of salinity notated with * were assumed as there was no information in the references about which value fits best to the experimental data.

Table 3. Wilting point and porosity according to soil texture from the NOAH land surface model with multi-parameterization options (NOAH-MP).

\begin{tabular}{cccc}
\hline SOIL TEXTURE & SAMPLE & $\mathbf{w}_{\mathbf{w p}}\left(\mathbf{c m}^{3} / \mathbf{c m}^{\mathbf{3}}\right)$ & $\mathbf{p}\left(\mathbf{c m}^{3} / \mathbf{c m}^{\mathbf{3}}\right)$ \\
\hline Sand & $\mathrm{A}, \mathrm{L}, \mathrm{U}, \mathrm{V}, \mathrm{W}$ & 0.010 & 0.339 \\
Loamy sand & $\mathrm{S}$ & 0.028 & 0.421 \\
Sandy loam & $\mathrm{D}, \mathrm{E}, \mathrm{T}$ & 0.047 & 0.434 \\
Silt loam & $\mathrm{F}$ & 0.084 & 0.476 \\
Silt & $\mathrm{B}, \mathrm{C}$ & 0.084 & 0.476 \\
Loam & $\mathrm{N}$ & 0.066 & 0.439 \\
Sandy clay loam & $\mathrm{Q}$ & 0.067 & 0.404 \\
Silty clay loam & $\mathrm{G}$ & 0.120 & $0.500^{*}$ \\
Clay loam & $\mathrm{O}$ & 0.103 & 0.465 \\
Sandy clay & - & 0.100 & 0.406 \\
Silty clay & $\mathrm{H}, \mathrm{M}$ & $0.2^{*}$ & $0.500^{*}$ \\
Clay & $\mathrm{I}, \mathrm{J}, \mathrm{K}, \mathrm{R}, \mathrm{X}$ & $0.2^{*}$ & $0.500^{*}$ \\
\hline
\end{tabular}

Wilting point and porosity from the State Soil Geographic (STATSGO) data $\left(\mathrm{cm}^{3} / \mathrm{cm}^{3}\right)$ [53] applied to the NOAH-MP land surface model; ${ }^{*}$ increased witling point and porosity to match the measurement points.

Table 4. Electrical conductivity of different soil textures [82].

\begin{tabular}{ccc}
\hline & $\boldsymbol{\sigma}^{\min }(\mathbf{S} / \mathbf{m})$ & $\boldsymbol{\sigma}^{\max }(\mathbf{S} / \mathbf{m})$ \\
\hline Sand & $0.3 \times 10^{-3}$ & $30 \times 10^{-3}$ \\
Silt & $4 \times 10^{-3}$ & $75 \times 10^{-3}$ \\
Clay & $20 \times 10^{-3}$ & $600 \times 10^{-3}$ \\
\hline
\end{tabular}

In order to find the fitting parameters $a$ and $b$ of Equation (32), the optimum $\varepsilon_{\text {bound }}^{\max }$ reaching the least RMSE (root-mean-square error) compared to the measured effective dielectric constant are determined from the wet soil A-I according to various authors from Table 2. The optimum value is the best combination of values for unknown bound water parameters $\varepsilon_{\text {bound, }}^{\max }$, assuming it is probably closest to the true soil condition. The $\varepsilon_{\text {bound }}^{\max }$ is determined when the RMSE becomes the minimum in the given clay contents as follows.

$$
\varepsilon_{\text {bound }}^{\max }=-36 \cdot \mathrm{v}_{\text {clay }}+44
$$


Regardless of the availability of bound water information, we are able to complete the prediction of the effective soil dielectric constant based on the measurements of volumetric clay contents owing to the proposed bound water model, Equations (25) and (26). Finally, our model can be tested based on soil texture, temperature and salinity information with the relevant formulas, as summarized in Table 5.

Table 5. Required formulas and data to compute the complex effective dielectric constant Equations (53)-(58).

\begin{tabular}{|c|c|c|}
\hline Physical Property & Symbol & Related Information \\
\hline Effective dielectric constant (real part) & $\varepsilon_{\text {eff }}^{\prime}$ & \multirow{2}{*}{$\begin{array}{l}\text { Equations (53)-(58): estimation in } \\
\text { simulation or measurement in retrieval }\end{array}$} \\
\hline Effective dielectric constant (imaginary part) & $\varepsilon^{\prime \prime}$ eff & \\
\hline Dry porosity & $\mathrm{p}$ & \multirow{2}{*}{ Values from Table 3} \\
\hline Wilting point & $\mathrm{w}_{\mathrm{wp}}$ & \\
\hline Volumetric mixing ratio of soil minerals & $\mathrm{V}_{\text {sand,clay,silt }}$ & Values from Table 2 \\
\hline Dielectric constant for sand (real part) & $\varepsilon^{\prime}$ sand & 3 from Table 6 \\
\hline Dielectric constant for clay, silt (real part) & $\varepsilon_{\text {clay, silt }}^{\prime}$ & 5 from Table 6 \\
\hline Dielectric constant for sand (imaginary part) & $\varepsilon^{\prime \prime}$ clay, silt,sand & 0.078 from Table 6 \\
\hline Soil water content $\left(\mathrm{mm}^{3} / \mathrm{mm}^{3}\right)$ & $\mathrm{w}$ & $\begin{array}{l}\text { Measurement in simulation } \\
\text { or estimation in retrieval }\end{array}$ \\
\hline Dielectric constant of bound water & $\varepsilon_{\text {bound }}^{\prime}, \varepsilon_{\text {bound }}^{\prime \prime}$ & $\begin{array}{l}\text { Equations (25) and (26) required } \\
\text { Equation (27), (33), (59) }\end{array}$ \\
\hline Dielectric constant of air & $\varepsilon_{\text {air }}^{\prime} \varepsilon^{\prime \prime}{ }_{\text {air }}$ & 1, 0 from Table 6 \\
\hline Angular frequency & $\omega$ & $2 \pi \mathrm{f}$ (e.g., $\mathrm{f}=1.4 \times 10^{9} \mathrm{~Hz}$ for L-band) \\
\hline Dielectric constant for free space & $\varepsilon_{0}$ & $8.8954187817 \times 10^{-12}$ \\
\hline Conductivity for bound and free water & $\sigma_{\text {bound,free }}$ & Equations (A13) and (A14) with Table 4 \\
\hline Conductivity for saline water at $25^{\circ} \mathrm{C}$ & $\sigma_{25^{\circ} \mathrm{C}}$ & $\begin{array}{l}\text { Equation (A10) with salinity S from } \\
\text { Table } 2\end{array}$ \\
\hline Empirical parameter & $\varphi$ & $\begin{array}{l}\text { Equation (A11) with temperature } \mathrm{T} \\
\text { from Table } 2\end{array}$ \\
\hline Conductivity for soil mineral & $\sigma_{\text {soil }}$ & Equation (A5) with Table 4 \\
\hline
\end{tabular}

\section{Results}

The performance of the new approach was assessed by comparison with experimental data, as well as with previous dielectric mixing models. The Wang and Schmugge model has a smaller dielectric constant for bound water compared to other approaches (see Table 6).

Table 6. Complex dielectric constant for land surface properties.

\begin{tabular}{|c|c|c|c|c|c|c|c|c|c|}
\hline \multirow[b]{2}{*}{ Microwave } & & \multicolumn{3}{|c|}{ Free Water } & \multicolumn{3}{|c|}{ Bound Water } & \multirow[b]{2}{*}{ Soil } & \multirow[b]{2}{*}{ Air } \\
\hline & & $\underset{1.4 \mathrm{GHz}}{\mathrm{L}}$ & $\begin{array}{c}\mathrm{C} \\
4,5,6 \\
\mathrm{GHz}\end{array}$ & $\underset{18 \mathrm{GHz}}{\mathrm{K}}$ & $\stackrel{\mathrm{L}}{1.4 \mathrm{GHz}}$ & $\begin{array}{c}\mathrm{C} \\
4,5,6 \\
\mathrm{GHz}\end{array}$ & $\begin{array}{c}\mathrm{K} \\
18 \mathrm{GHz}\end{array}$ & & \\
\hline \multirow{2}{*}{$\begin{array}{l}\text { Mironov et al. } \\
\text { (2009) }\end{array}$} & $\varepsilon^{\prime}$ & 99.5 & 93.7 & 43.9 & $37.7-79.1$ & $39.3-62.0$ & $19.2-29.8$ & $1.88-2.67$ & 1.0 \\
\hline & $\varepsilon^{\prime \prime}$ & 7.1 & 23.7 & 47.5 & $15.2-19.9$ & $19.2-22.6$ & $20.9-31.8$ & $0.002-0.13$ [78] A & 0.0 \\
\hline \multirow{2}{*}{$\begin{array}{l}\text { Mironov et al. } \\
\text { (2009), modified }\end{array}$} & $\varepsilon^{\prime}$ & 79.6 & 75.0 & 43.9 & * & * & * & * & 1.0 \\
\hline & $\varepsilon^{\prime \prime}$ & 5.6 & 18.7 & 37.5 & * & * & * & * & 0.0 \\
\hline \multirow{2}{*}{$\begin{array}{l}\text { Wang and } \\
\text { Schmugge }\end{array}$} & $\varepsilon^{\prime}$ & 79.6 & 73.1 & 41.3 & \multicolumn{3}{|c|}{3.15} & 5 & 1.0 \\
\hline & $\varepsilon^{\prime \prime}$ & 6.1 & 23.8 & 38.2 & \multicolumn{3}{|c|}{$0.0[52]$} & $0.078[81,83] \mathrm{B}$ & 0.0 \\
\hline \multirow[b]{2}{*}{ Dobson et al. } & $\varepsilon^{\prime}$ & 79.6 & 73.1 & 41.3 & \multirow{2}{*}{\multicolumn{3}{|c|}{$\begin{array}{c}35 \\
5[34]\end{array}$}} & 4.67 & 1.0 \\
\hline & $\varepsilon^{\prime \prime}$ & 6.1 & 23.8 & 38.2 & & & & $0[34] \mathrm{B}$ & 0.0 \\
\hline \multirow{2}{*}{ Proposed model } & $\varepsilon^{\prime}$ & 79.6 & 73.1 & 41.3 & \multirow{2}{*}{\multicolumn{3}{|c|}{$\begin{array}{l}\text { see Equation (25) } \\
\text { see Equation (26) }\end{array}$}} & 5.0 for $\varepsilon_{\text {clay, silt }}^{\prime} 3.0$ for $\varepsilon_{\text {sand }}^{\prime}$ & 1.0 \\
\hline & $\varepsilon^{\prime \prime}$ & 6.1 & 23.8 & 38.2 & & & & 0.078 for $\varepsilon^{\prime \prime}$ clay, silt,sand $[81,83] \mathrm{B}$ & 0.0 \\
\hline
\end{tabular}

The range of bound water dielectric constant computed from sand to clay; * same value as Mironov et al. (2009); value for porous Soil A and for solid Soil B. 
The model of Dobson et al. does not deal separately with bound and free water, but integrates them into a dielectric constant of water. For the comparison with Mironov et al. [53], we simulated the effective dielectric constant with Mironov et al. (2009) and Mironov et al. (2009), modified, which are defined at the end of Section 2.5. Because the purpose is the operational use of microwave remote sensing for soil moisture estimation on a global scale, the consistent performance of the dielectric prediction with high mean accuracy is decisive. Therefore, we validated the new approach with experiments in the L-band (Figure 5), C-band (Figure 6), K-band (Figure 7) and their RMSE analysis in Figure 8. Furthermore, we performed the prediction of the effective dielectric constant in a radiowave band at $30 \mathrm{MHz}$ (Figure 9) over various soil textures and provided the RMSE results in Figure 10. The average values are also listed in Table 7. Dobson's model [34] is based on the evaluation and calibration of five soil texture values from sandy loam to silt clay for which the sand mixing ratio ranged from $5-51 \%$. The simulation of pure sand with this model shows a too high dielectric constant in the real part (see Figure 5a), e.g., 27 instead of 18 for $w=0.275$. Other approaches, such as that of Wang and Schmugge [52] and that of Hallikainen et al. [49], generally underestimate the dielectric constant in such a situation and, therefore, result in too large values of soil moisture from the dielectric measurements. The values obtained with our model are in good agreement (e.g., only a $3 \%$ underestimation for $\mathrm{w}=0.275$ ) with the dielectric constant measurements of wet sand, also capturing the measurements above the porosity point. The models of Mironov et al. (2009) [53] and Hallikainen et al. [49] overestimate the imaginary part of the dielectric constant (e.g., $67 \%$ and $144 \%$ overestimated in $w=0.275$, respectively (see Figure $5 \mathrm{a}$ ), whereas other models including ours are closer to the measurements (e.g., an $18 \%$ overestimation for $\mathrm{w}=0.275$ ). When we compare the values obtained from the various models along the gradient of increasing clay content (see Figure 5a-i), the dielectric predictions for the real part are similar; in general, all of the predictions are mostly in reasonable agreement with the measured values of the dielectric constants. However, the models show significantly different performances in the prediction of the imaginary part. Considering the modeled curve for the imaginary part shown in Figure $5 b, g$, in the higher clay contents (Figure 5g), the predictions of various models diverge. The new model is in best agreement for both silt and silty clay loam with absolute RMSE values of only 0.34 and 0.48 , respectively. For the clay case (Figure $5 i$ ), the new model shows an overestimation. One of the possible reasons might be a swelling process of heavy clay in the oversaturated soil condition. A significantly larger porosity of the sampled clay soil than the value that we applied in our model (0.500, see Table 4) might explain this disagreement. 

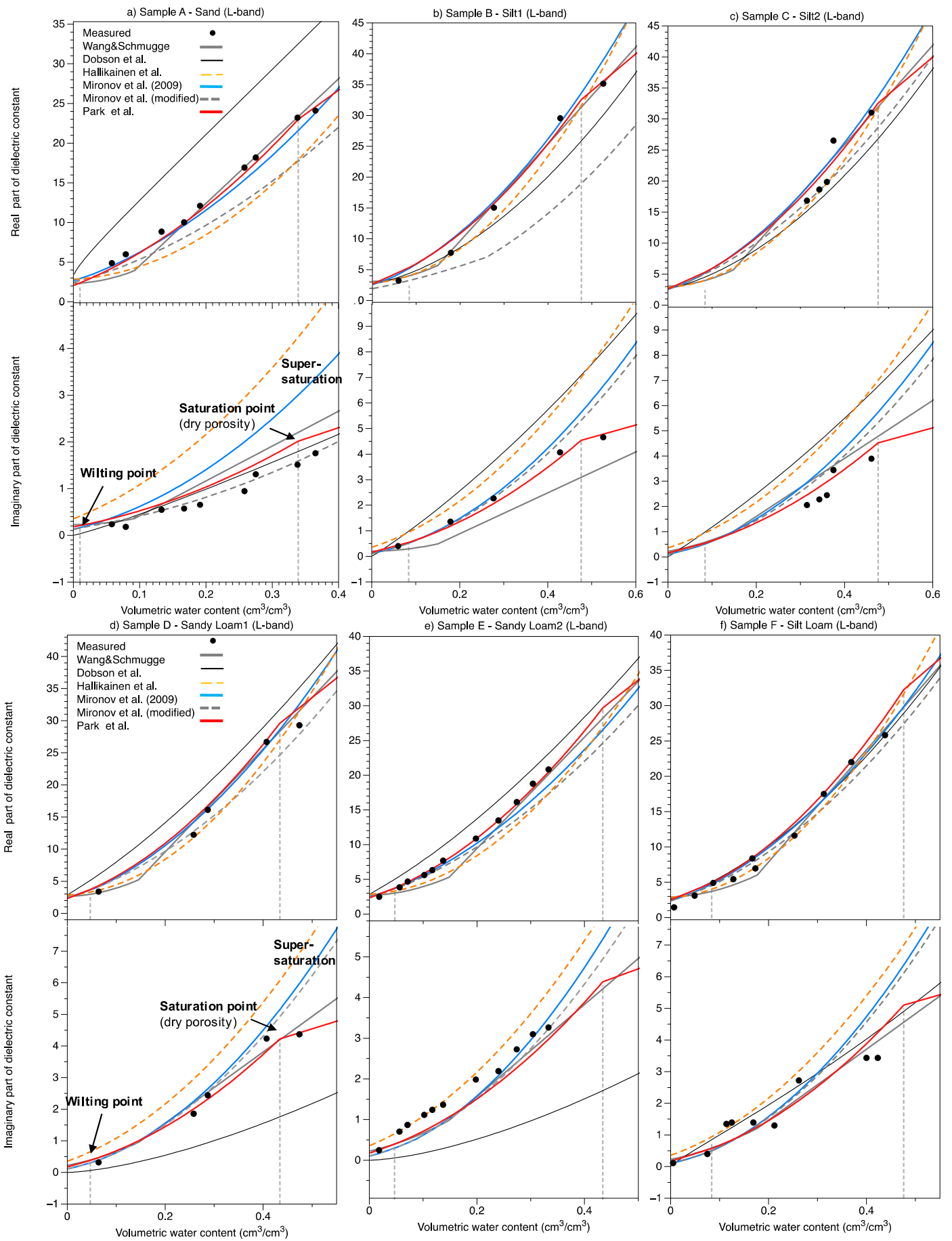

Figure 5. Cont. 

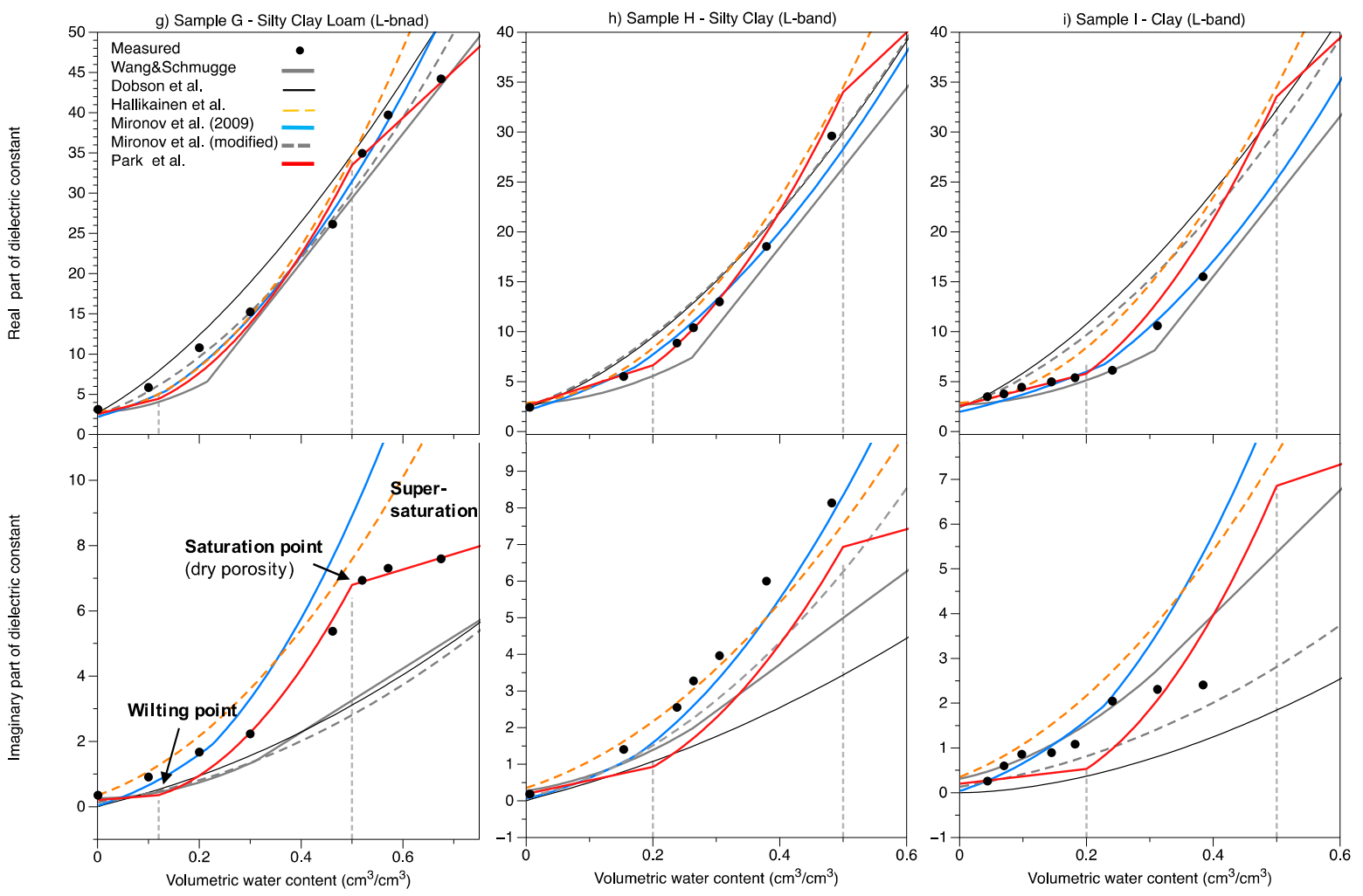

Figure 5. (a-i) Effective dielectric constant at 1.4 GHz (L-band) for nine soil samples from sand to clay (see Tables 1 and 2) from our approach, Wang and Schmugge, Dobson et al., Hallikainen et al. and Mironov et al. in comparison to measured data from [34,52,80,81]: vertical lines indicate $\mathrm{w}_{\mathrm{wp}}$ and $\mathrm{p}$.
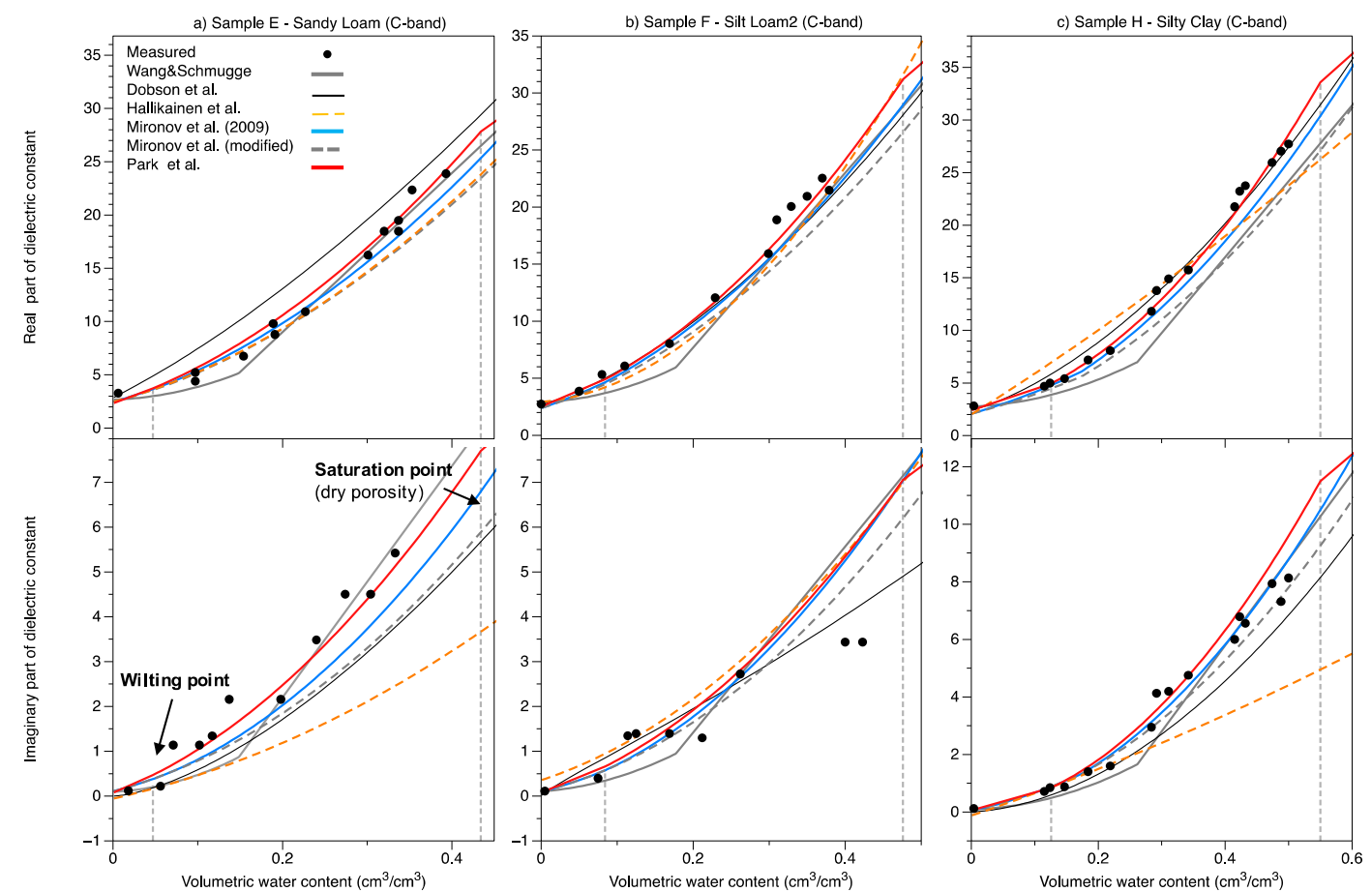

Figure 6. Same as Figure 5, but for the C-band: sandy loam at $5 \mathrm{GHz}$ (a); silt loam at $4 \mathrm{GHz}(\mathbf{b})$; as well as silty clay at $6 \mathrm{GHz}(\mathbf{c})$ and with measured data from $[34,49,66]$. 

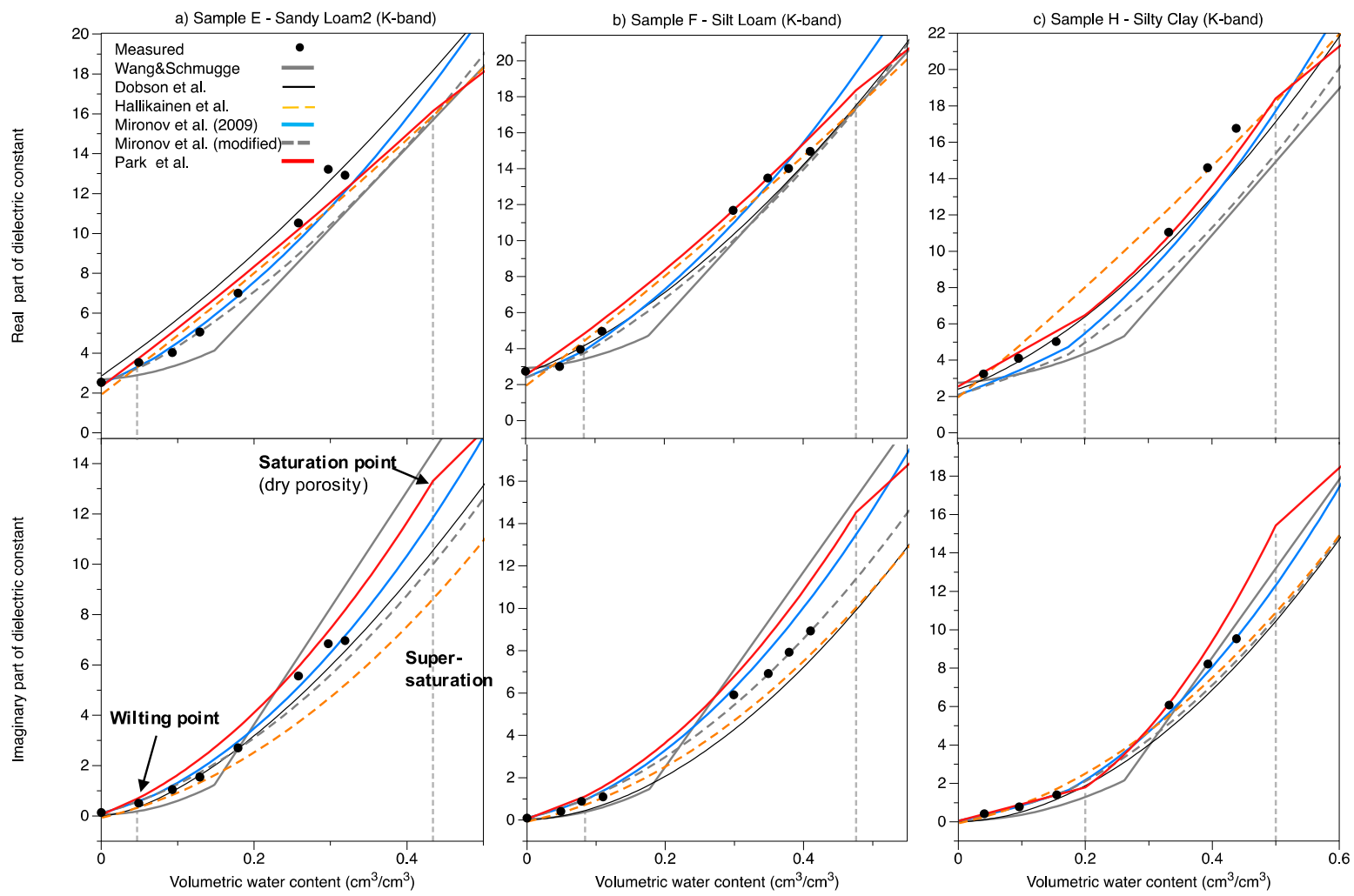

Figure 7. (a-c) Same as Figure 5, but for $18 \mathrm{GHz}$ (K-band) with measured data from [34] and [66].

Our new approach is more accurate even than the previous semi-empirical and empirical approaches (see the averaged analysis in Table 7 and Figure 8).

Table 7. Absolute and relative RMSE (root-mean-square error) score averaged (in \%) over different soil textures for L-, C- and K-band for the models H (Hallikainen et al. 1985) [49], D (Dobson et al. 1985) [34], M1 (Mironov et al. (2009) [53]), M2 (Mironov et al. (2009), modified), W (Wang and Schmugge 1980) [52] and $\mathrm{P}$ (the proposed model in this study). Gray boxes mark the best performance.

\begin{tabular}{cccccccc}
\hline Absolute RMSE & & $\boldsymbol{H}$ & $\mathbf{D}$ & $\mathbf{M 1}$ & $\mathbf{M 2}$ & $\boldsymbol{W}$ & $\boldsymbol{P}$ \\
\hline \multirow{3}{*}{ Real part } & $\mathrm{L}$ & 2.80 & 3.85 & 1.71 & 2.60 & 1.67 & 1.34 \\
& $\mathrm{C}$ & 2.03 & 1.77 & 1.62 & 2.55 & 2.02 & 0.90 \\
& $\mathrm{~K}$ & 0.87 & 0.99 & 1.00 & 1.58 & 1.81 & 1.38 \\
\hline Average & & $\mathbf{2 . 2 6}$ & $\mathbf{2 . 8 6}$ & $\mathbf{1 . 5 6}$ & $\mathbf{2 . 3 0}$ & $\mathbf{1 . 7 7}$ & $\mathbf{1 . 2 6}$ \\
\hline \multirow{3}{*}{ Imaginary part } & $\mathrm{L}$ & 1.39 & 1.67 & 1.11 & 1.02 & 0.78 & 0.47 \\
& $\mathrm{C}$ & 1.43 & 0.66 & 0.50 & 0.54 & 0.68 & 0.61 \\
& $\mathrm{~K}$ & 1.00 & 0.88 & 0.24 & 0.57 & 1.11 & 0.94 \\
\hline Average & & $\mathbf{1 . 3 0}$ & $\mathbf{1 . 2 7}$ & $\mathbf{0 . 8 2}$ & $\mathbf{0 . 8 8}$ & $\mathbf{0 . 8 3}$ & $\mathbf{0 . 5 9}$ \\
\hline Relative RMSE & & $\mathbf{H}$ & $\mathbf{D}$ & $\mathbf{M 1}$ & $\mathbf{M 2}$ & $\mathbf{W}$ & $\mathbf{P}$ \\
\hline \multirow{2}{*}{ Real part } & $\mathrm{L}$ & 20.8 & 28.9 & 10.6 & 16.5 & 11.8 & 9.8 \\
& $\mathrm{C}$ & 14.8 & 13.3 & 8.4 & 18.5 & 14.4 & 6.0 \\
\hline Average & $\mathrm{K}$ & 10.2 & 11.4 & 11.3 & 18.1 & 20.8 & 16.1 \\
\hline \multirow{2}{*}{ Imaginary part } & $\mathrm{L}$ & $\mathbf{1 7 . 5}$ & $\mathbf{2 2 . 3}$ & $\mathbf{1 0 . 3}$ & $\mathbf{1 7 . 2}$ & $\mathbf{1 4 . 1}$ & 10.5 \\
\hline Average & $\mathrm{C}$ & 50.3 & 62.7 & 51.9 & 47.5 & 30.3 & 21.8 \\
\hline & $\mathrm{K}$ & 27.2 & 22.8 & 21.1 & 21.1 & 28.0 & 24.3 \\
\hline
\end{tabular}




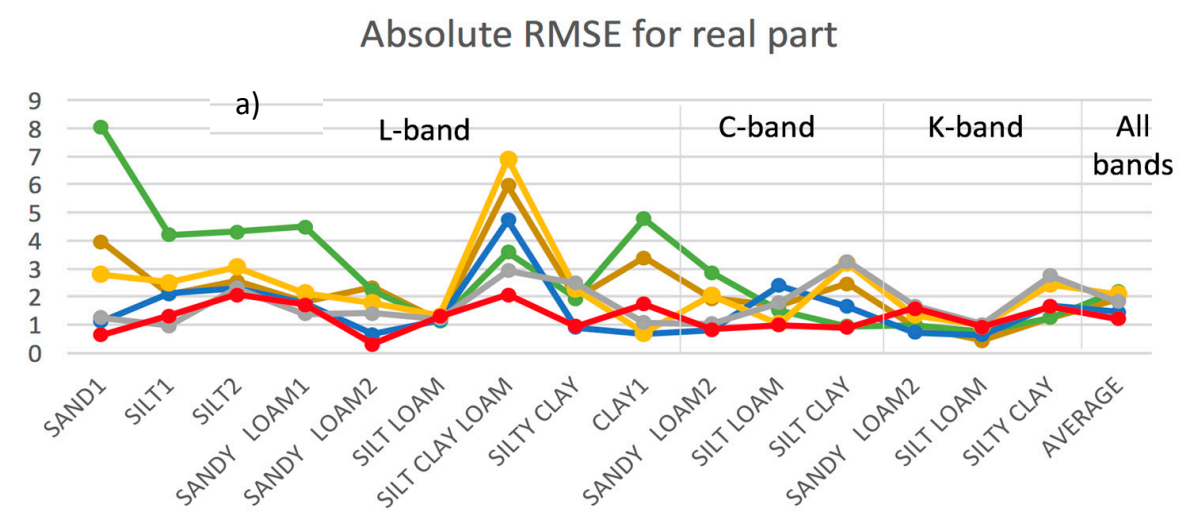

b)

Absolute RMSE for imaginary part

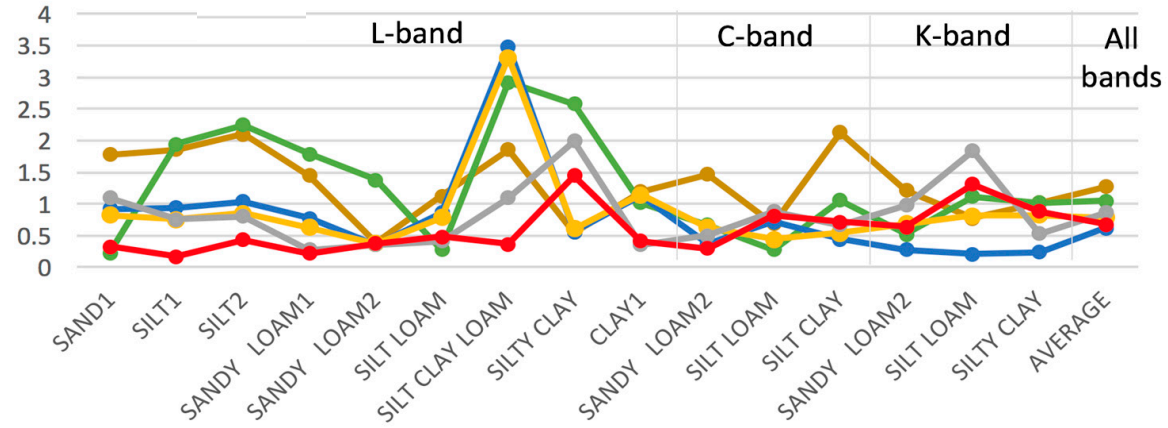

c) Relative RMSE for real part
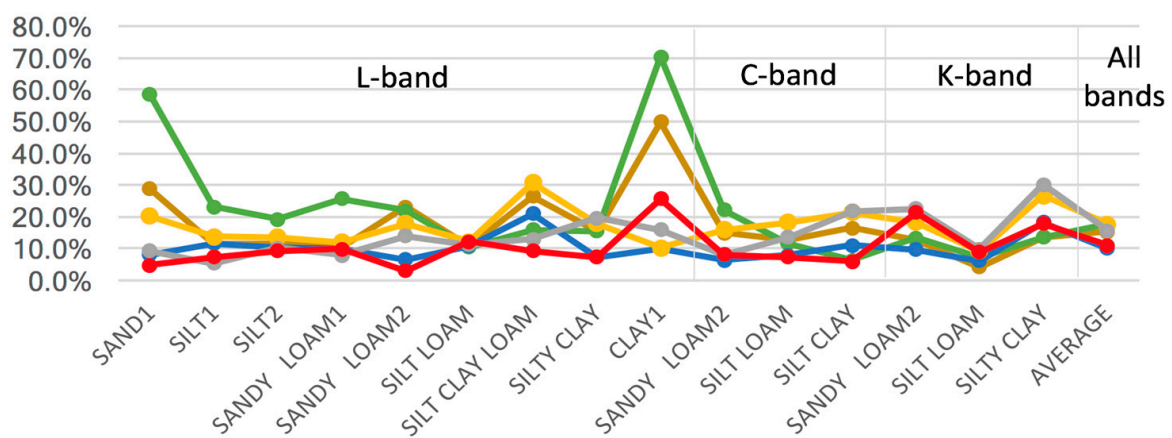

d) Relative RMSE for imaginary part

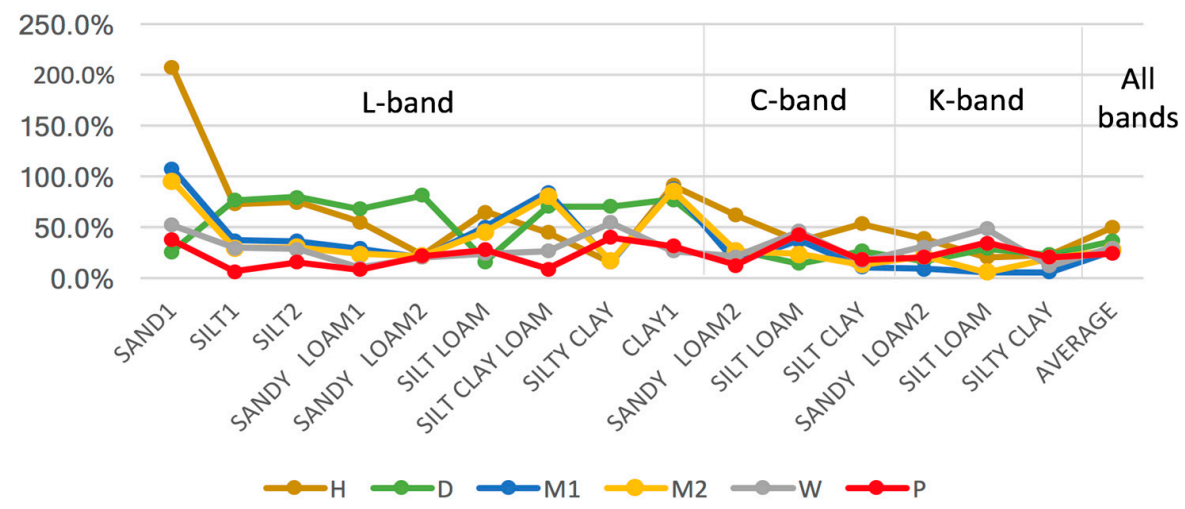

Figure 8. Absolute RMSE for the real part (a) and imaginary part (b) and relative RMSE (in \%) for the real part (c) and imaginary part (d) of the effective dielectric constant for different soil textures in the L-, C- and K-band for the models H [49], D [34], M1 [53], M2 (Mironov et al. (2009), modified), W [52] and $\mathrm{P}$ (this work). The last values show the overall RMSE. 

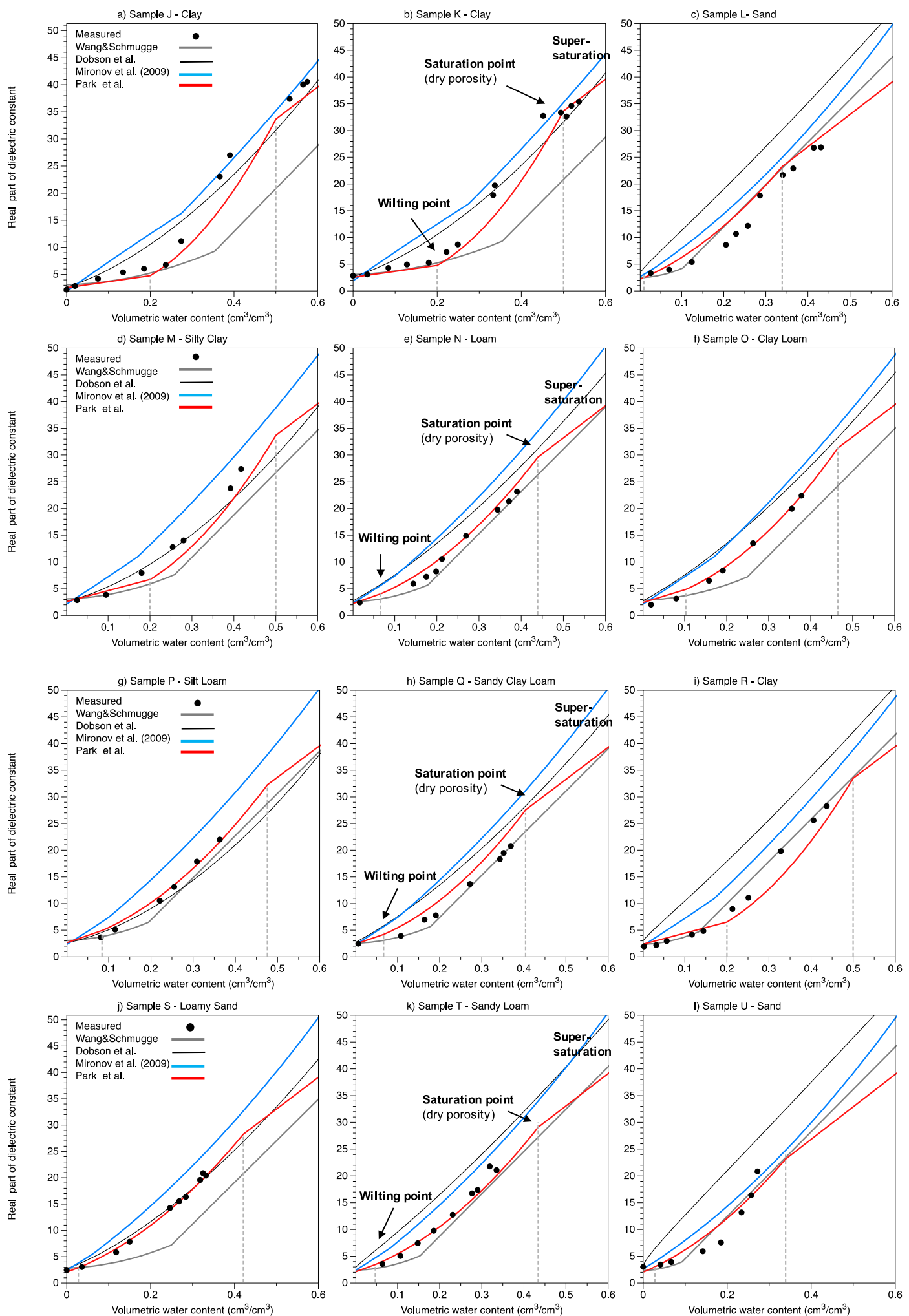

Figure 9. Cont. 

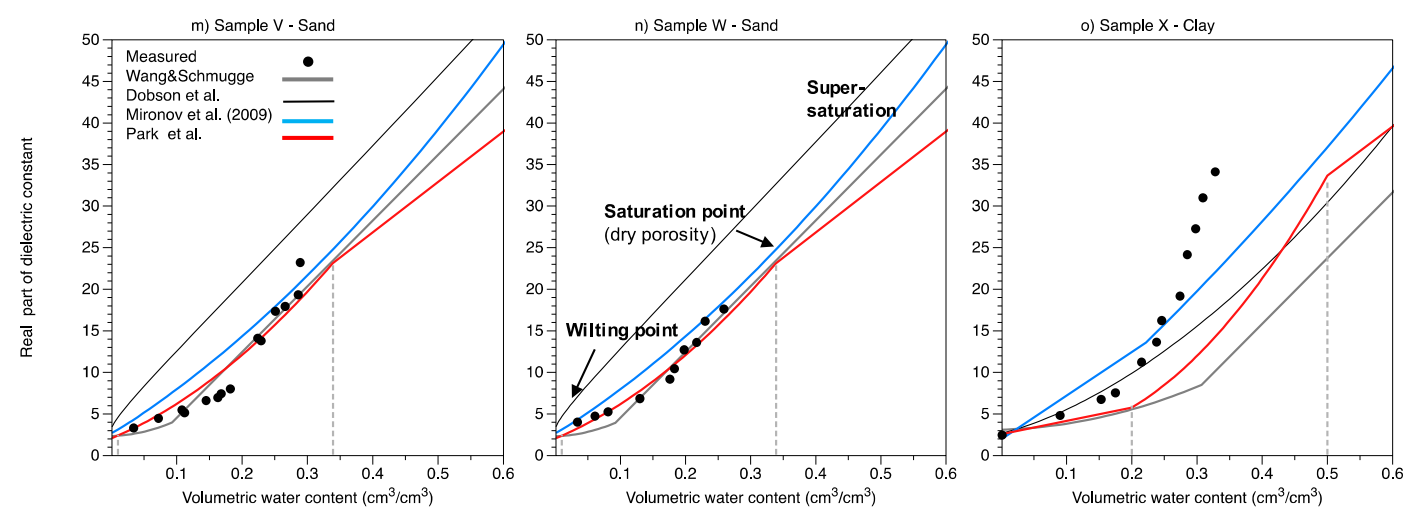

Figure 9. (a-o) Same as Figure 5, but prediction of microwave dielectric mixing models in the radiowave band $(30 \mathrm{MHz})$ with measured data from [48].

In the computation of the real part and the imaginary part in the L-band, our model is $22 \%$ and $59 \%$ more accurate than, e.g., Mironov et al. (2009) in terms of absolute RMSE and $8 \%$ and $58 \%$ in terms of relative RMSE, respectively. As this is the model used currently in SMAP and SMOS soil moisture retrieval algorithms, one may expect to improve these retrievals with the new model.

What is different from the previous models is that the new approach also includes the less frequent, but important case of oversaturation $(\mathrm{w}>\mathrm{p}$ ). Regardless of the limited measurement data for this case in the literature, we could validate the prediction in this range with data for sand (Figure 5a), silt (Figure 5b), sandy loam (Figure 5d) and silty clay loam (Figure 5g) obtained from [78,80].

The main purpose of this study is to create a permittivity model for an application in satellite remote sensing. The Debye relaxation model applied in this study enables us to predict the dielectric constant in various microwave wavelengths. Additionally, it was assessed to predict the observed permittivity in a typical radiowave band [48], as shown in Figure 10. For reference, the Hallikainen model was excluded from the prediction experiment in radio wave bands because the fitting parameters in the Hallikainen model are empirically determined only in the $\mathrm{L}, \mathrm{C}$ and $\mathrm{K}$ bands, rather than as a function of wavelength.

The results from Table 8 and Figure 10 show that the model presented in this study is more accurate than the other models at $30 \mathrm{MHz}$, the frequency at which the portable soil moisture sensors are applied. This is particularly clear in the samples J, K, L ((a,b,c) in Figure 10)) assumed to be in the form of swelling clay in w > p. In the case of Minorov et al. (2009), M1, which showed the most accurate prediction results after our model in the microwave, the model showed $40 \%$ higher RMSE than the proposed model in the radio wave prediction.

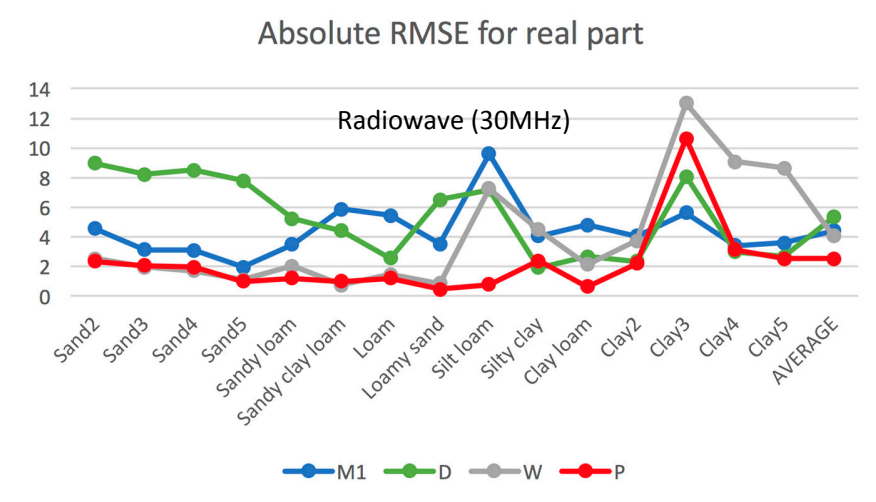

Figure 10. Absolute RMSE for the real part of the effective dielectric constant for different soil textures in the radiowave band for the models D [34], M1 [53], W [52] and P (this work). The last values show the overall RMSE. 
Table 8. Absolute RMSE over different soil textures in the radiowave band ( $30 \mathrm{MHz}$ ) for the models $\mathrm{D}$ (Dobson et al. 1985), M1 (Mironov et al. 2009), W (Wang and Schmugge 1980) and P (the proposed model in this study). Gray boxes mark the best performance.

\begin{tabular}{cccccc}
\hline Soil Texture & Samples & M1 & D & W & $\boldsymbol{P}$ \\
\hline Sand2 & L & 4.56 & 8.98 & 2.53 & 2.36 \\
Sand3 & U & 3.13 & 8.23 & 1.95 & 2.06 \\
Sand4 & V & 3.10 & 8.51 & 1.72 & 1.98 \\
Sand5 & W & 1.98 & 7.78 & 1.10 & 0.99 \\
Sandy loam & T & 3.49 & 5.24 & 2.02 & 1.20 \\
Sandy clay loam & Q & 5.86 & 4.41 & 0.77 & 0.99 \\
Loam & N & 5.43 & 2.55 & 1.46 & 1.21 \\
Loamy sand & S & 3.54 & 6.52 & 0.86 & 0.47 \\
Silt loam & P & 9.62 & 7.19 & 7.26 & 0.78 \\
Silty clay & M & 4.07 & 1.94 & 4.49 & 2.38 \\
Clay loam & O & 4.82 & 2.67 & 2.13 & 0.65 \\
Clay2 & J & 4.06 & 2.34 & 3.75 & 2.20 \\
Clay3 & K & 5.63 & 8.07 & 13.00 & 10.63 \\
Clay4 & R & 3.41 & 3.01 & 9.08 & 3.14 \\
Clay5 & X & 3.59 & 2.67 & 8.64 & 2.53 \\
AVERAGE & & 4.42 & 5.34 & 4.05 & 2.24 \\
\hline
\end{tabular}

\section{Discussion}

The range of $\mathrm{w}>\mathrm{p}$ is not covered in the existing models. Using the newly-proposed model, it is possible to improve the accuracy of the flood monitoring using the satellite and of the soil moisture estimation by the soil moisture probes even in the challenging circumstance such as the swelling or ponding condition. For example, the average RMSE of the new model in the samples A, B, D, G, J, K in Figures 5 and 9, considered that the case $\mathrm{w}>\mathrm{p}$ is included in those samples, is $36 \%, 77 \%$ and $42 \%$ lower than Mironov et al. (2009) in the prediction of the real and imaginary parts in the microwave band and of the real part in the radio wave band, respectively. However, the present version has been ideally designed according to twelve soil texture classification in which the wilting point and porosity of soil medium are also restricted to only twelve classes. In a real soil medium, because of its heterogeneous nature, not all soil particles reach the wilting point and porosity identically in the bulk of soil medium. For example, if the total water is measured as much as dry porosity, some of the portion can still be occupied with bound water defined in the formula for $\mathrm{w}<\mathrm{p}$, and others already can exceed the porosity point expanding water portion $\mathrm{w}>\mathrm{p}$. However, as is stated, the total amount of the soil water will be $\mathrm{p}$. If this heterogeneous nature of the soil medium is successfully reflected by the error function, a smoothing effect will appear where the discontinuity has been shown in the current model. However, the approach based on this strong assumption requires a verification based on the purposefully-designed experimental observations.

Through this kind of effort, the model proposed in this study can be improved as a continuous function mathematically differentiable at all points, which is an important requirement in the minimization process in the soil moisture retrieval algorithm of SMAP, SMOS and AMSR-E.

\section{Conclusions}

The physically-correct averaging method for the effective dielectric constant is the arithmetic mean because it follows the superposition rule of polarizability. We propose a new model for the effective dielectric constant of bare soil, which considers the soil water phase as consisting of free and bound water and the bulk behavior by including a damping factor. The resulting effective dielectric constant of bare soil shows a complex nonlinear behavior as a function of the volumetric fraction of water. In addition, our model allows for the calculation of the effective dielectric constant in the oversaturated soil condition. This should facilitate investigating surface runoff and the infiltration capacity of the surface and, thus, the tracking and forecast of flooding events. 
The new model can directly be applied to existing soil moisture estimation algorithms of TDR and GPR devices or to the baseline dielectric mixing model for satellite-borne instruments like SMOS, SMAP and AMSR-E, which should improve the accuracy of the data.

In the future, one can incorporate our dielectric mixing model into a radiative transfer model and the NOAH-MP land surface model [84] in order to simulate remote sensing observations of the brightness temperature. Using a forward operator consisting of a land surface model, dielectric mixing model and radiative transfer model, we expect to be able to evaluate the model performance in a more satisfactory way.

Previous models focused on the dielectric constant of wet soil below the saturation point. The simulation of the dielectric constant for $\mathrm{w}>\mathrm{p}$ had not been studied before. However, the measured dielectric constant values show a change in gradient when $w$ becomes larger than $\mathrm{p}$. The new model simulates dielectric constant data, which are linearly proportional to $\mathrm{w}$ for $\mathrm{w}>\mathrm{p}$ (see Equation (22)), whereas none of the previous models had this capability yet. For example, the approach of Mironov et al. [53], which is the current baseline dielectric mixing model both for SMOS [85] and SMAP satellites [86,87], shows that both the real and imaginary parts of the dielectric constant increase exponentially for $\mathrm{w}>\mathrm{p}$, which leads to too low $\mathrm{TB}$, particularly in the L-band; significant differences are found between our new model and previous models.

Overall, the results of the new model, as well as the data of previous models, namely of Wang and Schmugge [52], of Dobson et al. [34] and the most recent and most prevalent model of Mironov et al. [53], as well as the calibration approach of Hallikainen et al. [49], were compared as benchmarks with experimental data. It was found that the new model shows the lowest absolute and relative RMSE.

Acknowledgments: Financial support by German Research Foundation (DFG) International Research Training Group (IRTG) "GRK 1829" is gratefully acknowledged.

Author Contributions: All authors contributed to the writing of the manuscript. Volker Wulfmeyer is acknowledged for providing key directions and invaluable advice during this project. Andreas Behrendt has been involved in developing ideas within extensive discussions and editing the manuscript. Ellsworth LeDrew provided scientific counseling and discussions. Chang-Hwan Park established the dielectric mixing model, collected the data, performed the validation and compiled the manuscript.

Conflicts of Interest: The authors declare no conflict of interest.

\section{Appendix A. Polarizability and its Density}

The dielectric constant and refractive index are macroscopic averages of polarizabilities within an atom. Firstly, we consider the smaller scale average, polarizability. The total polarizability for a single molecule $\alpha$ is composed of orientational polarizability $\alpha_{\text {orient, }}$, ionic polarizability $\alpha_{\text {ionic }}$ and electronic polarizability $\alpha_{\text {elect }}[88]$ via:

$$
\alpha=\alpha_{\text {orient }}+\alpha_{\text {ionic }}+\alpha_{\text {elect }}
$$

Subsequently, we can express the total amount of homogenous molecular polarizability for the specific species $j$ (e.g., soil, air or water) by:

$$
\mathrm{N}_{\mathrm{j}} \alpha_{\mathrm{j}}=x_{\mathrm{j}}
$$

where $N_{j}$ is the number density of molecules of species $j, j$ is the order of species and the dielectric susceptibility $\chi_{j}$ for the species $j$. The total polarizability over all species in the mixture can be expressed with the effective susceptibility Equation (A3):

$$
\sum_{j=1}^{n} v_{j} N_{j} \alpha_{j}=\sum_{j=1}^{n} v_{j} \chi_{j}=\chi_{\text {eff }}
$$

where, $v_{j}$ is the volumetric mixing ratio of the species $j$ and the total volume of all species in the medium is $\sum_{j=1}^{n} v_{j}=1$. 
Finally, the electric susceptibility is reflected to the dielectric constant:

$$
\chi_{\text {eff }}=\varepsilon_{\text {eff }}-1
$$

The derivation explained above allows us to determine which of the mixing theories presented in Equations (1) and (2) are suitable for the calculation of the effective dielectric constant. In terms of the single molecular polarizability, the superposition principle is valid in Equation (A1). For a homogenous medium, $\alpha_{j}$ is proportional to $x_{j}$ Equation (A2). Then, we can superimpose $x_{j}$ with the mixing ratio $v_{j}$ Equation (A3) to calculate $\chi_{\text {eff }}$. The $\chi_{\text {eff }}$ is proportional to $\varepsilon_{\text {eff }}$ Equation (A4). In this manner, it was determined that the dielectric mixing approach Equation (1) is the physically valid average method. On the other hand, the refractive mixing approach represented by Equation (2) or the power law-based refractive mixing approach violates the superposition rule when the calculation has been examined down to the polarizability scale.

\section{Appendix B. Multiphase-Phase Mixing Model for Conductivity}

1. Soil:

The calculation of the effective conductivity was suggested empirically with the volumetric mixing ratio of a sand and clay [34], and the bulk electric conductivity of complex materials such as soil and sediments were also proposed [89]. The effective conductivity modeled by these approaches, however, additionally requires various fitting parameters depending on the soil texture and sediment types. By extending the proposed mixing model, we can derive effective soil conductivity without additional empirical parameters.

For the soil sub-phase, the parallel mixing for the finely-layered sand-shale sequence is a composite of sand, which has a very low electric conductivity, and shale, which has a very high electric conductivity [90]. In this study, we subdivide soil into dry soil and wet soil composed of clay, silt and sand. The dry soil effective conductivity $\sigma_{\text {soil }}$ consists of the sub-phases: sand $\sigma_{\text {sand }}^{\min }$, silt $\sigma_{\text {silt }}^{\min }$ and clay $\sigma_{\text {clay }}^{\min }$ (see Table 4 ) with their volumetric ratio v. ; thus:

$$
\sigma_{\text {soil }}=\mathrm{v}_{\text {sand }} \sigma_{\text {sand }}^{\min }+\mathrm{v}_{\text {silt }} \sigma_{\text {silt }}^{\min }+\mathrm{v}_{\text {clay }} \sigma_{\text {clay }}^{\text {min }}
$$

\section{Salinity:}

The effective conductivity of saline water is simply obtained from the contribution of pure water and the salt contents by assuming all salt is dissolved in water,

$$
\begin{gathered}
\sigma_{\text {saline }}=\mathrm{v}_{\text {water }} \sigma_{\text {water }}+\mathrm{v}_{\text {salt }} \sigma_{\text {salt }} \\
\mathrm{v}_{\text {water }}+\mathrm{v}_{\text {salt }}=1
\end{gathered}
$$

Bause the soil water includes almost no volumetric fraction for the solute, we can approximate the pure water sub-phase fraction $\mathrm{v}_{\text {water }}$. as one.

$$
\mathrm{V}_{\text {water }}=1-\mathrm{s} \frac{\rho_{\text {solute }}}{\rho_{\text {solution }}} \approx 1
$$

For the salinity part in (A6), we assume that the volumetric partial EC (electrical conductivity) contribution of the salinity $\mathrm{v}_{\text {saline }} \sigma_{\text {saline }}$ can approximate the ionic conductivity function of temperature T and salinity s [91].

$$
\mathrm{V}_{\text {salt }} \sigma_{\text {salt }}=\widetilde{\sigma}_{\text {salt }}=\sigma_{25^{\circ} \mathrm{C}}(\mathrm{s}) \mathrm{e}^{-\varphi(\mathrm{s}, 25-\mathrm{T})}
$$

where the ionic conductivity for sea water at $25{ }^{\circ} \mathrm{C}$ is provided by [91]:

$$
\sigma_{25^{\circ} \mathrm{C}}(\mathrm{s})=0.18252 \mathrm{~s}-1.4619 \times 10^{-3} \mathrm{~s}^{2}+2.093 \times 10^{-5} \mathrm{~s}^{3}-1.282 \times 10^{-7} \mathrm{~s}^{4}
$$


where $s$ is the salinity $(\%)$ and:

$$
\begin{aligned}
\varphi(\mathrm{s}, 25-\mathrm{T})= & (25 \\
& -\mathrm{T})\left(2.033 \times 10^{-2}+1.266 \times 10^{-4}(25-\mathrm{T})+2.464\right. \\
& \times 10^{-6}(25-\mathrm{T})^{2}-1.849 \times 10^{-5} \mathrm{~s}+2.551 \times 10^{-7}(25-\mathrm{T}) \mathrm{s} \\
& \left.-2.551 \times 10^{-8}(25-\mathrm{T})^{2} \mathrm{~s}\right)
\end{aligned}
$$

\section{Water:}

The effective conductivity for the soil water part is expressed in terms of the bound water and free water on soil particles.

$$
\sigma_{\text {water }}=\mathrm{v}_{\text {bound }} \sigma_{\text {bound }}+\mathrm{v}_{\text {free }} \sigma_{\text {free }}
$$

The value of EC differs considerably between bound water (counterions) and free water (electrolyte). Clavier et al. [92] suggested a value for the effective dielectric conductivity of soil including clay bound water and free water. We assume that the conductivity of bound water is equivalent to the conductivity of its bounded soil particles as shown in Equation (A13).

$$
\sigma_{\text {bound }} \approx \sigma_{\text {soil }}=\mathrm{v}_{\text {sand }} \sigma_{\text {sand }}^{\min }+\mathrm{v}_{\text {silt }} \sigma_{\text {silt }}^{\min }+\mathrm{v}_{\text {clay }} \sigma_{\text {clay }}^{\min }
$$

The conductivity of bound water $\sigma_{\text {bound }}$ in Equation (A12) is equivalent to the conductivity of the dry soil $\sigma_{\text {soil }}$ by the approximate relation Equation (A13). For the calculation of $\sigma_{\text {free }}$ using Equation (A14), the maximum EC value $\sigma^{\max }$ in Table 4 was chosen.

$$
\sigma_{\text {free }}=\mathrm{v}_{\text {sand }} \sigma_{\text {sand }}^{\max }+\mathrm{v}_{\text {silt }} \sigma_{\text {silt }}^{\max }+\mathrm{v}_{\text {clay }} \sigma_{\text {clay }}^{\text {max }}
$$

\section{References}

1. Vereecken, H.; Weihermüller, L.; Jonard, F.; Montzka, C. Characterization of crop canopies and water stress related phenomena using microwave remote sensing methods: A review. Vadose Zone J. 2012, 11. [CrossRef]

2. Wang, M.; Pan, N. Predictions of effective physical properties of complex multiphase materials. Mater. Sci. Eng. R Rep. 2008, 63, 1-30. [CrossRef]

3. Mossotti, O.F. Discussione analitica sull influenza che l'azione di un mezzo dielettrico ha sulla distribuzione dell'elettricita alla superficie di più corpi elettrici disseminati in esso. Memorie di Mathematica e di Fisica della Società Italiana della Scienza Residente in Modena 1850, 24, 49-74.

4. Rayleigh, L. LVI. On the influence of obstacles arranged in rectangular order upon the properties of a medium. Philos. Mag. 1892, 34, 481-502. [CrossRef]

5. Garnett, J.C.M. Colours in Metal Glasses and in Metallic Films. Philos. Trans. R. Soc. A 1904, 203, 385-420. [CrossRef]

6. Bruggeman, D.A.G. Berechnung Verschiedener Physikallischer Konstanten von Heterogenen Substanzen. Ann. Phys. 1935, 24, 636-664. [CrossRef]

7. Hamilton, R.; Crosser, O. Thermal conductivity of heterogeneous two-component systems. Ind. Eng. Chem. Fundam. 1962, 1, 187-191. [CrossRef]

8. Fricke, H. Mathematical treatment of the electrical conductivity and capacity of diverse system. Phys. Rev. 1924, 24, 575-587. [CrossRef]

9. Sillars, R. The properties of a dielectric containing semiconducting particles of various shapes. Inst. Electr. Eng.-Proc. Wirel. Sect. Inst. 1937, 12, 139-155.

10. Jackson, T.; Schmugge, T. Vegetation effects on the microwave emission of soils. Remote Sens. Environ. 1991, 36, 203-212. [CrossRef]

11. Schmugge, T.; Gloersen, P.; Wilheit, T.; Geiger, F. Remote sensing of soil moisture with microwave radiometers. J. Geophys. Res. 1974, 79, 317-323. [CrossRef]

12. Njoku, E.G.; Li, L. Retrieval of land surface parameters using passive microwave measurements at 6-18 GHz. IEEE Trans. Geosci. Remote Sens. 1999, 37, 79-93. [CrossRef] 
13. Owe, M.; de Jeu, R.; Holmes, T. Multisensor historical climatology of satellite-derived global land surface moisture. J. Geophys. Res. 2008, 113. [CrossRef]

14. Pause, M.; Lausch, A.; Bernhardt, M.; Hacker, J.; Schulz, K. Improving Soil Moisture Retrieval from Airborne L-band Radiometer Data by Considering Spatially Varying Roughness. Can. J. Remote Sens. 2014, just-accepted. [CrossRef]

15. De Jeu, R.A.; Holmes, T.R.; Panciera, R.; Walker, J.P. Parameterization of the Land Parameter Retrieval Model for L-Band Observations Using the NAFE'05 Data Set. IEEE Geosci. Remote Sens. Lett. 2009, 6, 630-634. [CrossRef]

16. Owe, M.; de Jeu, R.; Walker, J. A methodology for surface soil moisture and vegetation optical depth retrieval using the microwave polarization difference index. IEEE Trans. Geosci. Remote Sens. 2001, 39, 1643-1654. [CrossRef]

17. Meesters, A.G.; De Jeu, R.A.; Owe, M. Analytical derivation of the vegetation optical depth from the microwave polarization difference index. IEEE Geosci. Remote Sens. Lett. 2005, 2, 121-123. [CrossRef]

18. De Lannoy, G.J.; Reichle, R.H. Assimilation of SMOS brightness temperatures or soil moisture retrievals into a land surface model. Hydrol. Earth Syst. Sci. 2016, 20, 4895-4911. [CrossRef]

19. De Lannoy, G.J.; Koster, R.D.; Reichle, R.H.; Mahanama, S.P.; Liu, Q. An updated treatment of soil texture and associated hydraulic properties in a global land modeling system. J. Adv. Model. Earth Syst. 2014, 6, 957-979. [CrossRef]

20. Wigneron, J.-P.; Calvet, J.-C.; Pellarin, T.; Van de Griend, A.; Berger, M.; Ferrazzoli, P. Retrieving near-surface soil moisture from microwave radiometric observations: Current status and future plans. Remote Sens. Environ. 2003, 85, 489-506. [CrossRef]

21. Liou, Y.-A.; England, A.W. A land-surface process/radiobrightness model with coupled heat and moisture transport for freezing soils. IEEE Trans. Geosci. Remote Sens. 1998, 36, 669-677. [CrossRef]

22. Montzka, C.; Grant, J.P.; Moradkhani, H.; Franssen, H.-J.H.; Weihermüller, L.; Drusch, M.; Vereecken, H. Estimation of radiative transfer parameters from l-band passive microwave brightness temperatures using advanced data assimilation. Vadose Zone J. 2013, 12. [CrossRef]

23. Lu, H.; Yang, K.; Koike, T.; Zhao, L.; Qin, J. An improvement of the radiative transfer model component of a land data assimilation system and its validation on different land characteristics. Remote Sens. 2015, 7, 6358-6379. [CrossRef]

24. Parrens, M.; Mahfouf, J.-F.; Barbu, A.; Calvet, J.-C. Assimilation of surface soil moisture into a multilayer soil model: Design and evaluation at local scale. Hydrol. Earth Syst. Sci. 2014, 18, 673-689. [CrossRef]

25. De Rosnay, P.; Drusch, M.; Vasiljevic, D.; Balsamo, G.; Albergel, C.; Isaksen, L. A simplified Extended Kalman Filter for the global operational soil moisture analysis at ECMWF. Q. J. R. Meteorol. Soc. 2013, 139, 1199-1213. [CrossRef]

26. Reichle, R.H.; Ardizzone, J.V.; Kim, G.-K.; Lucchesi, R.A.; Smith, E.B.; Weiss, B.H. Soil Moisture Active Passive (SMAP) Mission Level 4 Surface and Root Zone Soil Moisture (L4_SM) Product Specification Document; Global Modeling and Assimilation Office, Earth Sciences Division, NASA Goddard Space Flight Center Greenbelt, Maryland 20771. Available online: https:/ /ntrs.nasa.gov/archive/nasa/casi.ntrs.nasa.gov/20160008107.pdf (accessed on 13 July 2017).

27. Reichle, R.H.; De Lannoy, G.J.; Liu, Q.; Ardizzone, J.V.; Chen, F.; Colliander, A.; Conaty, A.; Crow, W.; Jackson, T.; Kimball, J.; et al. Soil Moisture Active Passive Mission L4_SM Data Product Assessment (Version 2 Validated Release); NASA Goddard Space Flight Center: Greenbelt, MD, USA, 2016.

28. De Rosnay, P.; Calvet, J.-C.; Kerr, Y.; Wigneron, J.-P.; Lemaître, F.; Escorihuela, M.J.; Sabater, J.M.; Saleh, K.; Barrié, J.; Bouhours, G.; et al. SMOSREX: A long term field campaign experiment for soil moisture and land surface processes remote sensing. Remote Sens. Environ. 2006, 102, 377-389. [CrossRef]

29. Rowlandson, T.L.; Berg, A.A.; Bullock, P.R.; Ojo, E.R.; McNairn, H.; Wiseman, G.; Cosh, M.H. Evaluation of several calibration procedures for a portable soil moisture sensor. J. Hydrol. 2013, 498, 335-344. [CrossRef]

30. Brown, M.F. Dielectrics. In Encyclopedia of Physics; Springer: Berlin, Germany, 1956; Volume 17.

31. Birchak, J.R.; Gardner, C.; Hipp, J.; Victor, J. High dielectric constant microwave probes for sensing soil moisture. Proc. IEEE 1974, 62, 93-98. [CrossRef]

32. Fellner-Feldegg, H. Measurement of dielectrics in the time domain. J. Phys. Chem. 1969, 73, 616-623. [CrossRef] 
33. Ansoult, M.; De Backer, L.; Declercq, M. Statistical relationship between apparent dielectric constant and water content in porous media. Soil Sci. Soc. Am. J. 1984, 49, 47-50. [CrossRef]

34. Dobson, M.C.; Ulaby, F.T.; Hallikainen, M.T.; Elrayes, M.A. Microwave Dielectric Behavior of Wet Soil .2. Dielectric Mixing Models. IEEE Trans. Geosci. Remote Sens. 1985, 23, 35-46. [CrossRef]

35. Ledieu, J.; De Ridder, P.; De Clerck, P.; Dautrebande, S. A method of measuring soil moisture by time-domain reflectometry. J. Hydrol. 1986, 88, 319-328. [CrossRef]

36. Herkelrath, W.; Hamburg, S.; Murphy, F. Automatic, real-time monitoring of soil moisture in a remote field area with time domain reflectometry. Water Resour. Res. 1991, 27, 857-864. [CrossRef]

37. Ferré, P.; Rudolph, D.; Kachanoski, R. Spatial averaging of water content by time domain reflectometry: Implications for twin rod probes with and without dielectric coatings. Water Resour. Res. 1996, 32, 271-279. [CrossRef]

38. Malicki, M.; Plagge, R.; Roth, C. Improving the calibration of dielectric TDR soil moisture determination taking into account the solid soil. Eur. J. Soil Sci. 1996, 47, 357-366. [CrossRef]

39. Roth, K.; Schulin, R.; Flühler, H.; Attinger, W. Calibration of time domain reflectometry for water content measurement using a composite dielectric approach. Water Resour. Res. 1990, 26, 2267-2273. [CrossRef]

40. Jacobsen, O.H.; Schjonning, P. Comparison of TDR calibration functions for soil water determination. In Proceedings of the Symposium: TDR, Applications in Soil Science; Danish Institute for Plant and Soil Science: Foulum, Denmark, 1995; Volume 11.

41. Knoll, M.D. A Petrophysical Basis for Ground Penetrating Radar and Very Early Time Electromagnetics: Electrical Properties of Sand-Clay Mixtures. Ph.D. Thesis, University of British Columbia, Vancouver, BC, Canada, 1996.

42. Yu, C.; Warrick, A.; Conklin, M.; Young, M.; Zreda, M. Two-and three-parameter calibrations of time domain reflectometry for soil moisture measurement. Water Resour. Res. 1997, 33, 2417-2421. [CrossRef]

43. Kellner, E.; Lundin, L.-C. Calibration of time domain reflectometry for water content in peat soil. Nord. Hydrol. 2001, 32, 315-332.

44. Schaap, M.; Robinson, D.; Friedman, S.P.; Lazar, A. Measurement and modeling of the dielectric permittivity of layered granular media using time domain reflectometry. Soil Sci. Soc. Am. J. 2003, 67, 1113-1121. [CrossRef]

45. Kowalsky, M.B.; Finsterle, S.; Rubin, Y. Estimating flow parameter distributions using ground-penetrating radar and hydrological measurements during transient flow in the vadose zone. Adv. Water Resour. 2004, 27, 583-599. [CrossRef]

46. Robinson, D.; Jones, S.B.; Blonquist, J.; Friedman, S. A physically derived water content/permittivity calibration model for coarse-textured, layered soils. Soil Sci. Soc. Am. J. 2005, 69, 1372-1378. [CrossRef]

47. Topp, G.; Davis, J.; Annan, A.P. Electromagnetic determination of soil water content: Measurements in coaxial transmission lines. Water Resour. Res. 1980, 16, 574-582. [CrossRef]

48. Roth, C.; Malicki, M.; Plagge, R. Empirical evaluation of the relationship between soil dielectric constant and volumetric water content as the basis for calibrating soil moisture measurements by TDR. J. Soil Sci. 1992, 43, 1-13. [CrossRef]

49. Hallikainen, M.T.; Ulaby, F.T.; Dobson, M.C.; Elrayes, M.A.; Wu, L.K. Microwave Dielectric Behavior of Wet Soil-Part 1: Empirical-Models and Experimental-Observations. IEEE Trans. Geosci. Remote Sens. 1985, 23, 25-34. [CrossRef]

50. Tsang, L.; Kong, J.A.; Shin, R.T. Theory of Microwave Remote Sensing; Wiley-Interscience: New York, NY, USA, 1985.

51. Yoon, D.-H.; Zhang, J.; Lee, B.I. Dielectric constant and mixing model of BaTiO 3 composite thick films. Mater. Res. Bull. 2003, 38, 765-772. [CrossRef]

52. Wang, J.R.; Schmugge, T.J. An empirical model for the complex dielectric permittivity of soils as a function of water content. IEEE Trans. Geosci. Remote Sens. 1980, GE-18, 288-295. [CrossRef]

53. Mironov, V.L.; Kosolapova, L.G.; Fomin, S.V. Physically and mineralogically based spectroscopic dielectric model for moist soils. IEEE Trans. Geosci. Remote Sens. 2009, 47, 2059-2070. [CrossRef]

54. Todd, M.G.; Shi, F.G. Complex permittivity of composite systems: A comprehensive interphase approach. IEEE Trans. Dielectr. Electr. Insul. 2005, 12, 601-611. [CrossRef]

55. Palmer, L.S.; Cunliffe, A.; Hough, J.M. Dielectric constant of water films. Nature 1952, 796. [CrossRef] 
56. Mulla, D.J.; Cushman, J.H.; Low, P.F. Molecular dynamics and statistical mechanics of water near an uncharged silicate surface. Water Resour. Res. 1984, 20, 619-628. [CrossRef]

57. Wraith, J.M.; Or, D. Temperature effects on soil bulk dielectric permittivity measured by time domain reflectometry: Experimental evidence and hypothesis development. Water Resour. Res. 1999, 35, 361-369. [CrossRef]

58. Maréchal, Y. The Hydrogen Bond and the Water Molecule: The Physics and Chemistry of Water, Aqueous and Bio-Media; Elsevier: Amsterdam, , The Netherlands; Oxford, UK, 2007.

59. Gao, L.; Zhou, X.; Ding, Y. Effective thermal and electrical conductivity of carbon nanotube composites. Chem. Phys. Lett. 2007, 434, 297-300. [CrossRef]

60. Prasher, R.; Bhattacharya, P.; Phelan, P.E. Thermal conductivity of nanoscale colloidal solutions (nanofluids). Phys. Rev. Lett. 2005, 94, 025901. [CrossRef] [PubMed]

61. Bőttcher, C. Theory of Electric Polarisation; Elsevier: Amsterdam, The Netherlands, 1952.

62. Zimmerman, R.W. Thermal conductivity of fluid-saturated rocks. J. Pet. Sci. Eng. 1989, 3, 219-227. [CrossRef]

63. Klein, L.; Swift, C.T. An improved model for the dielectric constant of sea water at microwave frequencies. IEEE Trans. Antennas Propag. 1977, 25, 104-111. [CrossRef]

64. Lane, J.; Saxton, J. Dielectric dispersion in pure polar liquids at very high radio-frequencies. I. Measurements on water, methyl and ethyl alcohols. Proc. R. Soc. Lond. Ser. A Math. Phys. Sci. 1952, 213, 400-408. [CrossRef]

65. Stogryn, A. Equations for calculating the dielectric constant of saline water (Correspondence). IEEE Trans. Microw. Theory Tech. 1971, 19, 733-736. [CrossRef]

66. Boyarskii, D.; Tikhonov, V.; Komarova, N.Y. Model of dielectric constant of bound water in soil for applications of microwave remote sensing. Prog. Electromagn. Res. 2002, 35, 251-269. [CrossRef]

67. Loewer, M.; Igel, J.; Wagner, N. Spectral decomposition of soil electrical and dielectric losses and prediction of in situ GPR performance. IEEE J. Sel. Top. Appl. Earth Obs. Remote Sens. 2016, 9, 212-220. [CrossRef]

68. Jones, S.B.; Friedman, S.P. Particle shape effects on the effective permittivity of anisotropic or isotropic media consisting of aligned or randomly oriented ellipsoidal particles. Water Resour. Res. 2000, 36, 2821-2833. [CrossRef]

69. Chan, C.Y.; Knight, R.J. Determining water content and saturation from dielectric measurements in layered materials. Water Resour. Res. 1999, 35, 85-93. [CrossRef]

70. Chan, C.Y.; Knight, R.J. Laboratory measurements of electromagnetic wave velocity in layered sands. Water Resour. Res. 2001, 37, 1099-1105. [CrossRef]

71. Robinson, D.; Jones, S.B.; Wraith, J.; Or, D.; Friedman, S. A review of advances in dielectric and electrical conductivity measurement in soils using time domain reflectometry. Vadose Zone J. 2003, 2, 444-475. [CrossRef]

72. Kerr, Y.H.; Waldteufel, P.; Wigneron, J.-P.; Delwart, S.; Cabot, F.; Boutin, J.; Escorihuela, M.-J.; Font, J.; Reul, N.; Gruhier, C.; et al. The SMOS mission: New tool for monitoring key elements ofthe global water cycle. Proc. IEEE 2010, 98, 666-687. [CrossRef]

73. Entekhabi, D.; Njoku, E.G.; O’Neill, P.E.; Kellogg, K.H.; Crow, W.T.; Edelstein, W.N.; Entin, J.K.; Goodman, S.D.; Jackson, T.J.; Johnson, J.; et al. The soil moisture active passive (SMAP) mission. Proc. IEEE 2010, 98, 704-716. [CrossRef]

74. Schmugge, T.J. Remote sensing of soil moisture: Recent advances. IEEE Trans. Geosci. Remote Sens. 1983, GE-21, 336-344. [CrossRef]

75. Jackson, T.J.; O'Neill, P.E.; Swift, C.T. Passive microwave observation of diurnal surface soil moisture. IEEE Trans. Geosci. Remote Sens. 1997, 35, 1210-1222. [CrossRef]

76. Schmugge, T.J.; Kustas, W.P.; Ritchie, J.C.; Jackson, T.J.; Rango, A. Remote sensing in hydrology. Adv. Water Resour. 2002, 25, 1367-1385. [CrossRef]

77. Wilheit, T.T. Radiative transfer in a plane stratified dielectric. IEEE Trans. Geosci. Electron. 1978, 16, 138-143. [CrossRef]

78. Mironov, V.; Kerr, Y.; Wigneron, J.-P.; Kosolapova, L.; Demontoux, F. Temperature-and texture-dependent dielectric model for moist soils at 1.4 GHz. IEEE Geosci. Remote Sens. Lett. 2013, 10, 419-423. [CrossRef]

79. Uematsu, M.; Frank, E. Static dielectric constant of water and steam. J. Phys. Chem. Ref. Data 1980, 9, 1291-1306. [CrossRef] 
80. Curtis, J.O.; Weiss, C.A.; Everett, J.B. Effect of Soil Composition on Complex Dielectric Properties; DTIC Document, No. WES/TR/EL-95-34; US Army Crops of Engineer, Waterways Experiment Station: Vicksburg, MS, USA, 1995.

81. Ulaby, F.; Moore, R.; Fung, A. Microwave Remote Sensing: Active and Passive, Volume III, Volume Scattering and Emission Theory, Advanced Systems and Applications; Addison-Wesley Reading: Dedham, MA, USA, 1986.

82. Barbosa, R.N.; Overstreet, C. What is Soil Electrical Conductivity; Pub. 3185, 2/11 Report; LSU AgCenter: Baton Rouge, LA, USA, 2011.

83. Davis, J.; Annan, A. Ground-penetrating radar for high-resolution mapping of soil and rock stratigraphy1. Geophys. Prospect. 1989, 37, 531-551. [CrossRef]

84. Niu, G.Y.; Yang, Z.L.; Mitchell, K.E.; Chen, F.; Ek, M.B.; Barlage, M.; Kumar, A.; Manning, K.; Niyogi, D.; Rosero, E.; et al. The community Noah land surface model with multiparameterization options (Noah-MP): 1. Model description and evaluation with local-scale measurements. J. Geophys. Res. 2011, 116, D12109. [CrossRef]

85. Wigneron, J.-P.; Kerr, Y.; Waldteufel, P.; Saleh, K.; Escorihuela, M.-J.; Richaume, P.; Ferrazzoli, P.; De Rosnay, P.; Gurney, R.; Calvet, J.-C.; et al. L-band Microwave Emission of the Biosphere (L-MEB) Model: Description and calibration against experimental data sets over crop fields. Remote Sens. Environ. 2007, 107, 639-655. [CrossRef]

86. O'Neill, P.; Chan, S.; Njoku, E.; Jackson, T.; Bindlish, R. Algorithm Theoretical Basis Document Level 2 E 3 Soil Moisture (Passive) Data Products; Revision B; Jet Propulsion Lab., California Inst. Technol.: Pasadena, CA, USA.

87. Patton, J.C. Comparison of SMOS Vegetation Optical Thickness Data with the Proposed SMAP Algorithm; Iowa State University: Ames, IA, USA, 2014.

88. Sirdeshmukh, D.B.; Sirdeshmukh, L.; Subhadra, K. Atomistic Properties of Solids; Springer: Berlin, Germany, 2011.

89. Knödel, K.; Lange, G.; Voigt, H.-J. Environmental Geology: Handbook of Field Methods and Case Studies; Bundesanstalt für Geowissenschaften und, Ed.; Springer: Berlin, Germany, 2008.

90. Ellis, D.V.; Singer, J.M. Well Logging for Earth Scientists; Springer: Berlin, Germany, 2007.

91. Kerr, Y.; Waldteufel, P.; Richaume, P.; Davenport, I.; Ferrazzoli, P.; Wigneron, J. SMOS Level 2 Processor Soil Moisture Algorithm Theoretical Basis Document (ATBD); SM-ESL (CBSA): Toulouse, France, 2012.

92. Clavier, C.; Coates, G.; Dumanoir, J. Theoretical and experimental basis for the dual-water model for the interpretation of shaly sands. Soc. Pet. Eng. J. 1984, 9, 341-351. 